\title{
Evaluation of equivalent black carbon source apportionment using observations from Switzerland between 2008 and 2018
}

\author{
Stuart K. Grange ${ }^{1,2}$, Hanspeter Lötscher ${ }^{3}$, Andrea Fischer ${ }^{1}$, Lukas Emmenegger ${ }^{1}$, and Christoph Hueglin ${ }^{1}$ \\ ${ }^{1}$ Empa, Swiss Federal Laboratories for Materials Science and Technology, Überlandstrasse 129, 8600 Dübendorf, Switzerland \\ ${ }^{2}$ Wolfson Atmospheric Chemistry Laboratories, University of York, York, YO10 5DD, UK \\ ${ }^{3}$ Amt für Natur und Umwelt Graubünden, Gürtelstrasse 89, 7001 Chur, Switzerland
}

Correspondence: Stuart K. Grange (stuart.grange@empa.ch)

Received: 20 September 2019 - Discussion started: 19 November 2019

Revised: 15 March 2020 - Accepted: 17 March 2020 - Published: 14 April 2020

\begin{abstract}
Black carbon (BC) or soot is a constituent of particulate matter (PM) which is relevant for negative human health and climate effects, and despite the lack of direct legal limits, it is recognised as an important atmospheric pollutant to monitor, understand, and control. Aethalometers are instruments which continuously monitor BC by measuring absorption at a number of distinct wavelengths. If collocated elemental carbon (EC) observations are used to transform these values into $\mathrm{BC}$ mass, by convention, the result is named equivalent black carbon (EBC). BC emitted by different combustion processes has different optical absorption characteristics, and this can be used to apportion $\mathrm{EBC}$ mass into traffic $\left(\mathrm{EBC}_{\mathrm{TR}}\right)$ and woodburning $\left(\mathrm{EBC}_{\mathrm{WB}}\right)$ components with a data processing technique known as the aethalometer model. The aethalometer model was applied to six EBC monitoring sites across Switzerland (using data between 2008 and 2018) and was evaluated by investigating diurnal cycles, model coefficients, and ambient temperature dependence of the two EBC components. For one monitoring site, San Vittore, the aethalometer model failed to produce plausible outputs. The reason for this failure was likely due to a high load of freshly emitted wood smoke during the winter which should be thought of as a third distinct emission source. After model evaluation, the trend analysis indicated that $\mathrm{EBC}_{\mathrm{TR}}$ concentrations at the remaining five locations significantly decreased between 2008 and 2018. $\mathrm{EBC}_{\mathrm{WB}}$ also demonstrated significant decreases in most monitoring locations but not at a monitoring site south of the Alps with a high PM load sourced from biomass burning. Ratios of EBC and particulate matter with a diameter of less than $2.5 \mu \mathrm{m}\left(\mathrm{PM}_{2.5}\right)$ suggested that EBC contributes $6 \%-14 \%$ of the $\mathrm{PM}_{2.5}$ mass
\end{abstract}

in Switzerland. The aethalometer model is a useful data analysis procedure but can fail under certain conditions; thus, careful evaluation is required to ensure the method is robust and suitable in other locations.

\section{Introduction}

\subsection{Black carbon}

Atmospheric particulate matter (PM) has a variety of components, one of which is black carbon (BC), which is commonly referred to as soot. BC is strongly light absorbing (hence the name), is generally found in the fine PM fraction (PM with a diameter less than $2.5 \mu \mathrm{m} ; \mathrm{PM}_{2.5}$ ) and is generated by the incomplete combustion of fuels (Hansen et al., 1984; Vignati et al., 2010). Biomass burning, internal combustion engines (especially those which are fuelled by diesel), and industrial processes can all be $\mathrm{BC}$ emission sources (Bond et al., 2004; Jacobson, 2001). There are no known BC generation or degradation processes in the atmosphere, and because the only removal mechanisms for BC are wet and dry deposition, $\mathrm{BC}$ has a lifetime of several days to weeks in the atmosphere. These attributes make $\mathrm{BC}$ a reliable tracer for combustion processes.

$\mathrm{BC}$ is an important atmospheric pollutant to consider in its own sense however (Anenberg et al., 2012). BC is believed to have a positive (warming) climate forcing effect due to the absorption of radiation and the reduction of albedo, especially when deposited on snow and ice (Ramanathan and Carmichael, 2008; Weinhold, 2012; Bond et al., 2013). BC is harmful to human health, and there is evidence that $\mathrm{BC}$ 
is a particularly potent PM component when considering deleterious health effects due to the aerosol's large surfacearea-to-mass ratio, tendency to be enriched with harmful organic compounds, and ability to penetrate deep into the lungs (Janssen et al., 2011; De Prins et al., 2014; Laeremans et al., 2018). The International Agency for Research on Cancer (IARC) has also classed soot as a Group 1 carcinogen, indicating there is clear evidence that soot causes cancer in humans (International Agency for Research on Cancer, 2019). It is difficult however to tease apart the health effects of BC alone from PM as a whole (Jacobson, 2001; European Environment Agency, 2013). These features have made BC an important pollutant to monitor, understand, manage, and control despite not currently having direct legal limits imposed in Europe and elsewhere (Reche et al., 2011; European Environment Agency, 2016).

\subsection{Aethalometers and the aethalometer model}

$\mathrm{BC}$ is measured, sampled, or monitored in a variety of ways, but the most widespread method is the use of aethalometers (Hansen et al., 1984). Aethalometers are described in depth elsewhere; however, briefly they are optical instruments which sample air continuously and deposit the PM onto filter material. The loaded filter is illuminated; the light attenuation is measured as an optical absorption; and the increase in attenuation over time is logged and used to calculate $\mathrm{BC}$ concentrations with empirical coefficients. The quartz filter material used by aethalometers can reach saturation, so the instruments employ a filter-tape system where the filter material is advanced if saturation occurs or when a threshold of elapsed time has passed. Continuously depositing aerosol onto a filter causes artefacts known as filter-scattering and filter-shadowing effects, but there are standard algorithms to compensate for these effects, some of which are applied on board by the instrument as part of the measurement cycle (Magee Scientific, 2016).

Modern aethalometers used in ambient air quality monitoring networks are multi-wavelength models measuring absorption between the near-ultraviolet (UV) and the nearinfrared (IR) range, at distinct wavelengths within this range. BC sourced from different families of combustion processes demonstrate different absorption features. Most notably, woodburning particles, i.e. wood smoke, generally contain a rich organic component which is very effective at absorbing light in the UV range, while diesel soot shows a weaker spectral dependence (Kirchstetter et al., 2004) (Fig. 1).

The spectral dependence of the light absorption can be described by $b_{\text {abs }} \propto \lambda^{-\alpha}$, where $b_{\text {abs }}$ is the absorption, $\lambda$ is the wavelength, and $\alpha$ is the Ångström exponent (Moosmüller et al., 2011; Harrison et al., 2013). The $\alpha$ value is the exponential slope of a regression model for absorption as a function of wavelength; $\alpha$ for woodburning-sourced $\mathrm{BC}$ results in higher values due to the increased absorption in the UV

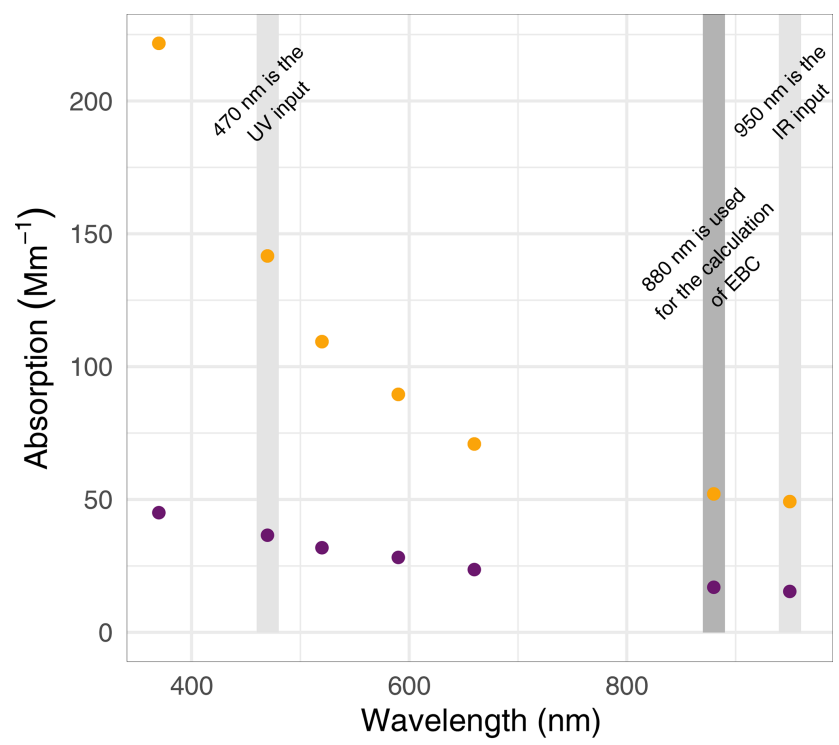

$$
\text { Site - } \begin{aligned}
& \text { Bern-Bollwerk } \\
& \text { (traffic) }
\end{aligned} \text { - } \begin{aligned}
& \text { Magadino-Cadernazzo } \\
& \text { (woodburning) }
\end{aligned}
$$

Figure 1. Demonstration of different aethalometer absorption dependence on wavelengths for two monitoring sites in Switzerland with distinct aerosol characteristics. Data have been filtered to a single observation (hourly) to show the dependence on the dominating sources, and the 470, 880, and $950 \mathrm{~nm}$ channels are highlighted and explained in text. Magadino-Cadenazzo has a stronger absorption in the UV region due to woodburning emissions.

region when compared to $\mathrm{BC}$ emitted by vehicular sources (Fig. 1).

The different spectral dependences between these sources can be leveraged with a data processing technique called the aethalometer model, first reported by Sandradewi et al. (2008a) but used many times since in many locations; for examples, see Sandradewi et al. (2008b), Favez et al. (2009), Herich et al. (2011), and Fuller et al. (2014). In routine aethalometer use, only the $880 \mathrm{~nm}$ absorption wavelength is used with a fixed coefficient (called a mass absorption coefficient discussed in Sect. 2.2), which is the strict definition of BC. The aethalometer model uses UV and IR measurements to represent the two sources, and the wavelengths used are usually 470 and $950 \mathrm{~nm}$ for the UV and IR channels respectively (also shown in Fig. 1; Zotter et al., 2017). UV and IR $\alpha$ values are also required for the source apportionment and need to be carefully chosen on a case-by-case basis however. The aethalometer model simply uses information which is generally discarded in most monitoring applications, and the barrier for entry to the method is low.

\subsection{Black carbon nomenclature note}

The nomenclature and vocabulary used for $\mathrm{BC}$ is diverse and can lead to confusion (Andreae and Gelencsér, 2006; Petzold et al., 2013). Here, we refer to BC determined by opti- 
cal measurement techniques, i.e. by aethalometers and transformed with the use of collocated elemental carbon (EC) observations as equivalent black carbon (EBC). This definition has been recommended by the Global Atmospheric Watch (Tarasova, 2012). When EBC is apportioned into its traffic and woodburning components, the TR and WB subscript notation is used respectively, i.e. $\mathrm{EBC}_{\mathrm{TR}}$ and $\mathrm{EBC}_{\mathrm{WB}}$. If total $\mathrm{EBC}$ needs to be used for clarity against the EBC components, $\mathrm{EBC}_{\mathrm{TOT}}$ is used. This notation is consistent with Zotter et al. (2017), which this work somewhat extends. When discussing emissions of soot, BC is still used however because $\mathrm{EBC}$ is only an operational definition and does not refer to the pollutant.

\subsection{Objectives}

The primary objective of this work is to apply the aethalometer model data transformation technique to apportion longterm (up to 10 years) EBC time series from six Swiss monitoring sites into two components - a traffic and a woodburning component $\left(\mathrm{EBC}_{\mathrm{TR}}\right.$ and $\left.\mathrm{EBC}_{\mathrm{WB}}\right)$ - and evaluate the method's performance. The suitability and limitations of the aethalometer model as a technique to employ before trend analysis will be discussed. A data set is presented where the aethalometer model fails to apportion the two EBC components correctly. This is done to demonstrate the features which will be present if the aethalometer model is inadequate for a particular application, and it outlines that although the aethalometer model is a useful technique, it is not a panacea. The second objective is to expose the $\mathrm{EBC}_{\mathrm{TR}}$ and $\mathrm{EBC}_{\mathrm{WB}}$ components to a trend analysis and document the features observed in the Swiss time series.

\section{Methods}

\subsection{Data}

Absorption observations measured by aethalometers for six monitoring sites in Switzerland were analysed (Table 1; Fig. 2). The monitoring sites were either part of the federal monitoring network (National Air Pollution Monitoring Network; NABEL) or networks run by the Swiss Cantonal authorities (states; Federal Office for the Environment, 2014). Sites were classified as either urban traffic, urban background, rural, or rural mountain according to their surrounds. Four of the sites were located on the Swiss plateau (where the majority of the human population is located), but Rigi-Seebodenalp, despite being located on the plateau, is at altitude (1031 m; Fig. 2). Two monitoring sites, MagadinoCadenazzo and San Vittore, are located south of the Alps in valleys where residential woodburning is much more common than on the Swiss plateau due to its rural nature (Alfarra et al., 2007; Szidat et al., 2007).

The absorption observations were measured by two models of multi-wavelength aethalometers manufactured by
Magee Scientific. The two models were the AE31 and AE33, which measure adsorption at seven wavelengths: 370, 470, $520,590,660,880$, and $950 \mathrm{~nm}$. The AE31 is an earlier generation instrument discontinued in 2016 (Magee Scientific, 2017), while the AE33 aethalometer replaced the AE31 and is currently manufactured (Magee Scientific, 2019). These two aethalometer models share the same measurement principle; however the newer AE33 uses a "dual-spot" approach to allow for a superior method to compensate for filterloading effects (Drinovec et al., 2015). The differences between the AE31 and AE33 technologies mean that the algorithms which compensate or correct for filter-shadowing effects and filter-loading effects are different. Notably, data from AE31 must be compensated for such effects with a postprocessing procedure, while the AE33's algorithms are conducted on board as part of the measurement cycle. For the full description of the compensation procedures, see Weingartner et al. (2003) and Drinovec et al. (2015). Quartz filters were used by the aethalometers, and therefore, a multiple light-scattering factor (denoted as $C$ ) of 2.14 was used (Weingartner et al., 2003). There were 13 distinct aethalometers used in the monitoring network which were irregularly cycled among the monitoring sites as part of the networks' maintenance procedures (Table 2). All aethalometers were operated with $\mathrm{PM}_{2.5}$ sample inlets.

Data from the aethalometers for five of the six Swiss EBC monitoring sites were queried from the NABEL monitoring network's database, while the remaining site's observations, at San Vittore, were provided directly by the Graubünden canton's environmental department (Amt für Natur und Umwelt). All absorption observations had been compensated for the filter-loading and shadowing effects with the instrument model's respective algorithms before this analysis was undertaken as part of the monitoring networks' operations (Weingartner et al., 2003; Drinovec et al., 2015). Generally, the observations were stored as hourly means, but for the data which were at a higher resolution (10 and 30 min means), observations were aggregated to create a consistent hourly time series which was used for analysis.

The standard procedure for absorption monitoring data was for 10 and 30 min means to be calculated from $1 \mathrm{~min}$ observations which were logged on site directly from the instruments. All aggregations required data capture thresholds of $60 \%$ for a valid summary to be calculated. Additional quality control and assurance procedures were undertaken quarterly including the cleaning of the inlet, leak testing, and cleaning of the analytical zone of the instruments. The responses of the AE33 instruments were also checked with optical reference filters regularly. The data were ratified on a monthly basis and compared across the different measurement sites along with other air pollutants, and suspicious measurements were invalidated. The raw instrument outputs are archived but are not routinely used in the data processing within the NABEL monitoring network. However, the raw data can be consulted in case of questions concerning data quality. 
Table 1. Information about the six equivalent black carbon (EBC) monitoring sites in Switzerland which were used in this study.

\begin{tabular}{|c|c|c|c|c|c|c|c|c|c|}
\hline Site & Site name & $\begin{array}{l}\text { Local } \\
\text { ID }\end{array}$ & Site type & Start date & End date & $\begin{array}{c}\text { Days } \\
\text { online }\end{array}$ & Latitude & Longitude & $\begin{array}{r}\text { Elevation } \\
(\mathrm{m})\end{array}$ \\
\hline ch0031a & Bern-Bollwerk & BER & Urban traffic & 11 Dec 2013 & 31 Dec 2018 & 1846 & 46.951 & 7.441 & 536 \\
\hline $\operatorname{ch} 0002 r$ & Payerne & PAY & Rural & $4 \operatorname{Mar} 2008$ & 31 Dec 2018 & 3954 & 46.813 & 6.944 & 489 \\
\hline $\operatorname{ch} 0033 a$ & Magadino-Cadenazzo & MAG & Rural & 13 Mar 2008 & 31 Dec 2018 & 3945 & 46.160 & 8.934 & 203 \\
\hline $\operatorname{ch} 2001 \mathrm{e}$ & San Vittore & SVI & Rural & 4 Oct 2013 & 31 Dec 2018 & 1914 & 46.239 & 9.105 & 298 \\
\hline
\end{tabular}

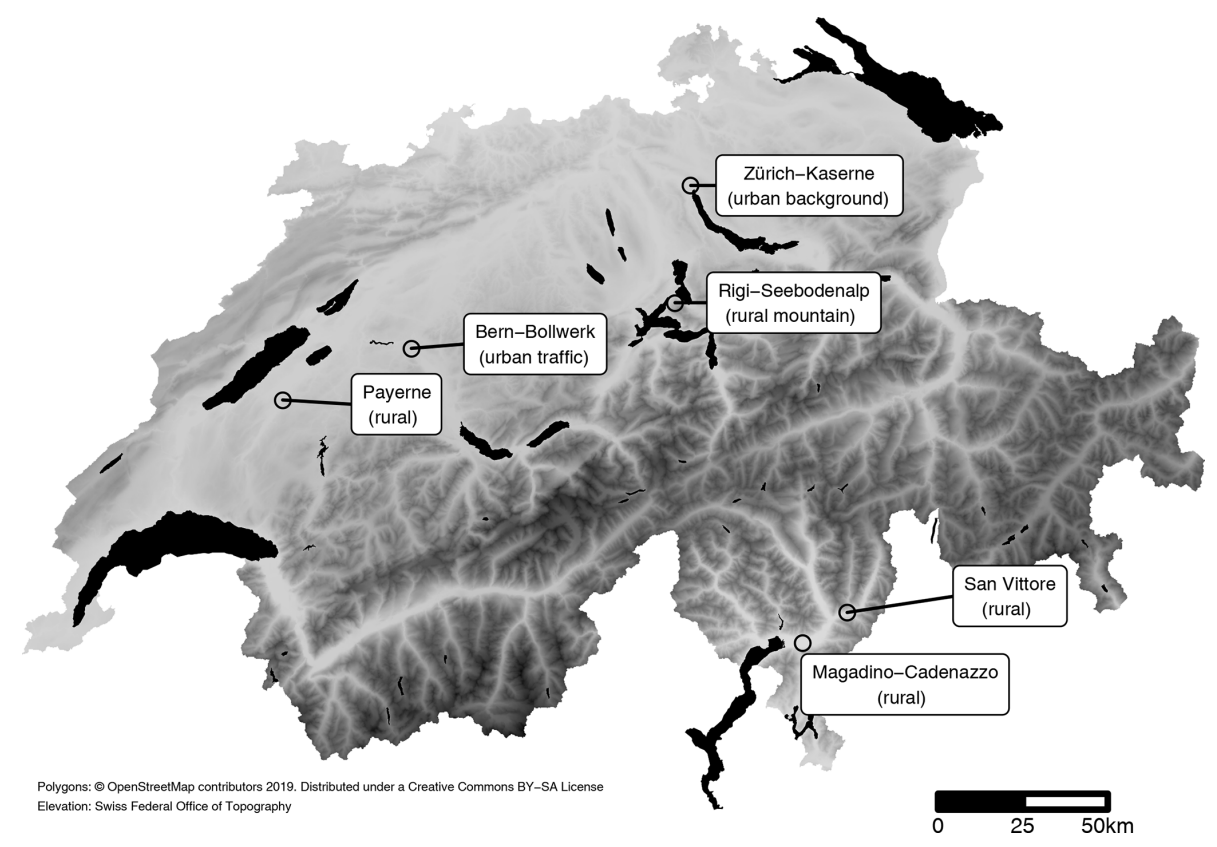

Figure 2. The six Swiss equivalent black carbon (EBC) monitoring sites used in the analysis and their site classifications. Solid black areas are significant water bodies, and shading represents the terrain and elevation. The boundaries of Switzerland and the lakes were extracted from (C) OpenStreetMap (OpenStreetMap contributors, 2019), and the heights were derived from Switzerland's digital height model (Swiss Federal Office of Topography, 2010).

The method employed to transform absorption observations to EBC requires elemental carbon (EC) concentrations. EC was determined by the standard EN16909 thermaloptical transmission (TOT) method using the EUSAAR2 temperature protocol (European Committee for Standardization, 2017). Unlike the continuous observations which the aethalometers provided, EC concentrations were available as daily samples and ranged from being sampled every 4 to $12 \mathrm{~d}$. When using aethalometer and EC data together, the aethalometer observations were aggregated (as arithmetic means) to daily resolution (midnight to midnight) to ensure that the observations spanned the same time period and duration. Only days with both EC and absorption observations were used for these comparisons because interpolation of the less frequent EC data was not attempted. The EC samples were also collected with $\mathrm{PM}_{2.5}$ inlets. $\mathrm{PM}_{2.5}$ observations for the monitoring sites were required to calcu- late the $\mathrm{EBC} / \mathrm{PM}_{2.5}$ ratios. These data were accessed with the saqget $r \mathrm{R}$ package, which gives access to the $\mathrm{Eu}-$ ropean Commission's AirBase and Air Quality e-Reporting (AQER) repositories in a convenient way (European Environment Agency, 2014, 2019; Grange, 2019b). Only daily validated data were kept for analysis with most of the observations being sourced from high-volume samplers.

The analysis presented covered a period between March 2008 and the end of 2018, but the start date of the aethalometer operation varied among the different monitoring sites (Tables 1, 2). All absorption observations, site metadata, and instrument locations data are publicly accessible in a persistent data repository (Grange, 2020).

\subsection{Source apportionment}

The absorption data from the aethalometers were apportioned into two components: the traffic fraction $\left(\mathrm{EBC}_{\mathrm{TR}}\right)$ and 
Table 2. Aethalometer instruments' locations between 2007 and 2018. Dates have been rounded to the nearest hour, and those end dates which are missing show that the instrument was on site until the end of the analysis period (the end of 2018).

\begin{tabular}{|c|c|c|c|c|c|}
\hline Site & Site name & Local ID & Start date & End date & Instrument ID \\
\hline ch0031a & Bern-Bollwerk & BER & 10 Dec 2013, 16:00:00 & 13 Mar 2014, 10:00:00 & AE33-S02-00136 \\
\hline ch0031a & Bern-Bollwerk & BER & 13 Mar 2014, 09:00:00 & 14 Mar 2014, 16:00:00 & AE33-S01-00092 \\
\hline ch0031a & Bern-Bollwerk & BER & 14 Mar 2014, 15:00:00 & $27 \mathrm{Jul} 2016,11: 00: 00$ & AE31-768:0701 \\
\hline ch0031a & Bern-Bollwerk & BER & $27 \mathrm{Jul} 2016,15: 00: 00$ & 26 Oct $2016,10: 00: 00$ & AE31-718:0605 \\
\hline ch0031a & Bern-Bollwerk & BER & 26 Oct $2016,10: 00: 00$ & $6 \mathrm{Jul} 2017,11: 00: 00$ & AE31-768:0701 \\
\hline ch0031a & Bern-Bollwerk & BER & 6 Jul 2017, 10:00:00 & 22 Mar 2018, 12:00:00 & AE31-719:0605 \\
\hline ch0031a & Bern-Bollwerk & BER & 22 Mar 2018, 11:00:00 & 29 Nov $2018,12: 00: 00$ & AE31-768:0701 \\
\hline ch0031a & Bern-Bollwerk & BER & 29 Nov $2018,10: 00: 00$ & & AE33-S07-00736 \\
\hline ch0010a & Zürich-Kaserne & ZUE & 2 Apr 2009, 10:00:00 & 8 Oct $2009,11: 00: 00$ & AE31-769:0701 \\
\hline ch0010a & Zürich-Kaserne & ZUE & 8 Oct $2009,10: 00: 00$ & $25 \mathrm{Jul} 2011,14: 00: 00$ & AE31-768:0701 \\
\hline ch0010a & Zürich-Kaserne & ZUE & 25 Jul 2011, 13:00:00 & 31 Aug 2012, 14:00:00 & AE31-719:0605 \\
\hline ch0010a & Zürich-Kaserne & ZUE & 31 Aug 2012, 10:00:00 & 5 Jun 2013, 13:00:00 & AE31-768:0701 \\
\hline ch0010a & Zürich-Kaserne & ZUE & 5 Jun 2013, 12:00:00 & 10 Apr $2014,11: 00: 00$ & AE31-718:0605 \\
\hline ch0010a & Zürich-Kaserne & ZUE & 10 Apr 2014, 10:00:00 & & AE33-S01-00092 \\
\hline $\operatorname{ch} 0002 r$ & Payerne & PAY & 4 Mar 2008, 15:00:00 & 14 May 2008, 09:00:00 & AE31-768:0701 \\
\hline $\operatorname{ch} 0002 r$ & Payerne & PAY & 21 May 2008, 09:00:00 & 2 Oct $2008,16: 00: 00$ & AE31-768:0701 \\
\hline $\operatorname{ch} 0002 \mathrm{r}$ & Payerne & PAY & 2 Oct $2008,15: 00: 00$ & 4 Apr 2013, 12:00:00 & AE31-718:0605 \\
\hline $\operatorname{ch} 0002 \mathrm{r}$ & Payerne & PAY & 4 Apr 2013, 11:00:00 & 27 Jun $2013,13: 00: 00$ & AE31-719:0605 \\
\hline $\operatorname{ch} 0002 \mathrm{r}$ & Payerne & PAY & 27 Jun $2013,12: 00: 00$ & 16 Sep 2015, 12:00:00 & AE31-769:0701 \\
\hline $\operatorname{ch} 0002 \mathrm{r}$ & Payerne & PAY & 16 Sep 2015, 12:00:00 & 8 Jun $2016,16: 00: 00$ & AE31-719:0605 \\
\hline $\operatorname{ch} 0002 \mathrm{r}$ & Payerne & PAY & 8 Jun 2016, 10:00:00 & & AE33-S04-00430 \\
\hline ch0033a & Magadino-Cadenazzo & MAG & 13 Mar 2008, 12:00:00 & 17 Jun $2008,12: 00: 00$ & AE31-769:0701 \\
\hline ch0033a & Magadino-Cadenazzo & MAG & 3 Jul 2008, 13:00:00 & 28 Aug 2008, 10:00:00 & AE31-769:0701 \\
\hline ch0033a & Magadino-Cadenazzo & MAG & 28 Aug 2008, 11:00:00 & $5 \operatorname{Dec} 2008,11: 00: 00$ & AE31-719:0605 \\
\hline ch0033a & Magadino-Cadenazzo & MAG & 18 Dec 2008, 11:00:00 & 25 Mar 2010, 12:00:00 & AE31-719:0605 \\
\hline ch0033a & Magadino-Cadenazzo & MAG & 25 Mar 2010, 11:00:00 & 12 Jun 2013, 13:00:00 & AE31-769:0701 \\
\hline ch0033a & Magadino-Cadenazzo & MAG & 12 Jun $2013,13: 00: 00$ & 18 Dec 2013, 13:00:00 & AE31-768:0701 \\
\hline ch0033a & Magadino-Cadenazzo & MAG & 18 Dec 2013, 14:00:00 & 12 Jun 2014, 09:00:00 & AE31-719:0605 \\
\hline ch0033a & Magadino-Cadenazzo & MAG & 12 Jun 2014, 09:00:00 & 21 Jan $2016,11: 00: 00$ & AE31-718:0605 \\
\hline ch0033a & Magadino-Cadenazzo & MAG & 21 Jan 2016, 10:00:00 & $21 \operatorname{Dec} 2016,10: 00: 00$ & AE31-769:0701 \\
\hline ch0033a & Magadino-Cadenazzo & MAG & $21 \operatorname{Dec} 2016,10: 00: 00$ & 24 May 2017, 11:00:00 & AE33-S00-00060 \\
\hline ch0033a & Magadino-Cadenazzo & MAG & 24 May 2017, 10:00:00 & & AE33-S04-00429 \\
\hline $\operatorname{ch} 2001 \mathrm{e}$ & San Vittore & SVI & 4 Oct 2013, 00:00:00 & & AE33-S02-00133 \\
\hline ch0005r & Rigi-Seebodenalp & RIG & 22 Jan 2013, 14:00:00 & 30 May 2013, 13:00:00 & AE33-S00-00049 \\
\hline $\operatorname{ch} 0005 r$ & Rigi-Seebodenalp & RIG & 30 May 2013, 10:00:00 & 12 Nov $2015,12: 00: 00$ & AE33-S00-00060 \\
\hline ch0005r & Rigi-Seebodenalp & RIG & 12 Nov 2015, 11:00:00 & & AE33-S02-00136 \\
\hline
\end{tabular}

the woodburning fraction $\left(\mathrm{EBC}_{\mathrm{WB}}\right)$ with the aethalometer model (Sandradewi et al., 2008a). The aethalometer model is based on the principle that EBC emitted from woodburning activities has an enhanced absorption in the UV range relative to EBC sourced from the combustion of fossil fuels. A critical component of applying the aethalometer model to produce valid outputs is the selection of the Ångström exponents (which are the slopes of exponential regression models), usually denoted by $\alpha$ (Harrison et al., 2013). Fortunately, in Switzerland, the Ångström exponents for woodburning and traffic sources have been determined robustly using ${ }^{14} \mathrm{C}$ observations of the EC fraction across Switzerland between 2005 and 2012 (Zotter et al., 2017). Here we use 0.9 and 1.68 for $\alpha_{\mathrm{TR}}$ and $\alpha_{\mathrm{WB}}$ respectively, as recommended by Zotter et al. (2017).
Mass absorption cross-section (MAC) coefficients are required to transform optical absorption observations to EBC mass (Magee Scientific, 2016). The instrument manufacturers use fixed MAC values on board to calculate $\mathrm{BC}$ mass (for example the A33's factory MAC values are displayed in Table A1), but any given MAC value is a function of PM size and morphology which will change depending on the PM source (Zotter et al., 2017). For the trend analysis reported here, the MAC values for absorption at the $950 \mathrm{~nm}$ wavelength (used for the IR input to the aethalometer model) were calculated with rolling simple least-squares linear regression models between absorption and the mass of EC in the $\mathrm{PM}_{2.5}$ fraction. A least-squares estimator was used because EC was determined with a reference method and is accepted without uncertainty. The window was $180 \mathrm{~d}$ (with 
centre alignment), and this logic was implemented with the z०० R package (Zeileis and Grothendieck, 2005).

Once the Ångström exponents were chosen and the MAC values were calculated, the aethalometer model was applied to the absorption observations at hourly resolution, and the $\mathrm{R}$ function used for this transformation is available (Grange, 2019a). Based on the absorption at 470 and $950 \mathrm{~nm}$ (UV and IR spectra respectively), this resulted in three EBC mass variables for each valid absorption observation: $\mathrm{EBC}_{\mathrm{WB}}, \mathrm{EBC}_{\mathrm{TR}}$, and $\mathrm{EBC}_{\text {TOT. }}$. A flow diagram which represents the data processing steps can be found in Fig. A1.

\subsection{Trend tests}

Formal trend tests were performed on the EBC components with the Theil-Sen slope estimator, a robust, non-parametric estimator provided by the openair R package (Carslaw and Ropkins, 2012). Before the trend was tested, the observations were aggregated to a monthly resolution and deseasonalised with loess models to extract the trend component $(\mathrm{R}$ Core Team, 2019). Autocorrelation was taken into account, resulting in conservative slope estimations, and all trend tests were conducted at the 0.05 significance level.

\section{Results and discussion}

\subsection{Model coefficient evaluation}

\subsubsection{Mass absorption cross-section (MAC) coefficients}

The MAC values which were empirically derived using least-squares regression models (using EC and absorption at $950 \mathrm{~nm}$ ), with a $180 \mathrm{~d}$ rolling window showing substantial variability (Fig. 3). This suggests that the use of fixed or static MAC values is questionable for trend analysis applications. The sites' MAC values at $950 \mathrm{~nm}$ had an average of $11.3 \pm 2.9 \mathrm{~m}^{2} \mathrm{~g}^{-1}$ during the analysis period despite the irregular cycling of different instruments among the sites (Table 2). For perspective, compare this range with the factory MAC values displayed in Table A1. A seasonal pattern was present in the MAC values where summertime absorption measures were higher than those in wintertime, which represents a change of average aerosol characteristics during the year, which is to be expected. The range of the seasonality was as low as $0.4 \mathrm{~m}^{2} \mathrm{~g}^{-1}$ at Zürich-Kaserne but as high as $2.3 \mathrm{~m}^{2} \mathrm{~g}^{-1}$ at Magadino-Cadenazzo (Fig. A2). The seasonal variation was also accompanied by intra-instrumental variation.

The MAC values for Rigi-Seebodenalp were atypical and showed a substantial decrease between 2013 and 2016 (Fig. 3). During this period, the same aethalometer was operating at the monitoring location (Table 2; Fig. A3). The MAC value is an empirical coefficient which represents aerosol composition, and it is very unlikely that Rigi-Seebodenalp's aerosol characteristics altered dramatically between 2013 and 2016; therefore the observed decrease in the MAC value was almost certainly an instrument artefact - perhaps a slow degradation in sensitivity. Indeed, the decrease in the MAC value stopped when the instrument was replaced in late 2015 and remained low for the rest of the monitoring period (Fig. A3). This instrument-derived feature was only uncovered due to the presence of collocated EC observations, but due to a lack of additional data, we do not wish to speculate further on what was the cause for this decline in the MAC coefficient, and this may warrant further investigation elsewhere.

The rolling least-squares regression procedure presented here ensures that the changes in MAC over time are compensated for before EBC mass is calculated with the aethalometer model. The changes or drift in the MAC values, especially for Rigi-Seebodenalp, are not propagated into the EBC masses using this method. Therefore, this approach is recommended over using fixed MAC values if EC time series are available and trend analysis is to be undertaken with several years of aethalometer observations.

\subsection{2 Ångström exponents $(\alpha)$}

A critical input for the aethalometer model is the $\alpha$ values used for the traffic- and woodburning-sourced EBC (Harrison et al., 2013). The $\alpha$ values used here were previously derived from comparing ${ }^{14} \mathrm{C}$ and $\mathrm{EC}$ observations (Sect. 2.2; Zotter et al. (2017)), but to validate if the values were sensible for the sites analysed, $\alpha$ was calculated for each hourly absorption observation, and their distributions were investigated. Here, $\alpha$ was calculated by the curve fitting of all absorption wavelengths $(370,470,520,590,660,880$, and $950 \mathrm{~nm}$ ) with exponential regression models.

The distributions of the calculated $\alpha$ values were consistent with those reported by Zotter et al. (2017), which were 0.9 and 1.68 for $\alpha_{\mathrm{TR}}$ and $\alpha_{\mathrm{WB}}$ respectively. Fig. 4 shows the $\alpha$ distributions for three of the monitoring sites along a continuum of increasing woodburning activity (from left to right). The distributions for $\alpha$ at each of the monitoring sites peaked at 1.2, the value used for $\alpha_{\mathrm{TR}}$ in the aethalometer model. However, as the monitoring sites' were exposed to a progressively higher woodburning PM load, the distribution become positively skewed. Magadino-Cadenazzo for example, a site which is exposed to wood smoke, has a tail which extends beyond 1.68, while the urban-traffic Bern-Bollwerk site's $\alpha$ distribution contains only a small component at, and beyond, the $\alpha_{\text {WB }}$ value of 1.68. Therefore, the features of the $\alpha$ distributions can be rather informative for diagnostic purposes.

San Vittore's calculated $\alpha$ values were unique because they displayed a bimodal distribution which was not present at the other monitoring sites (Fig. 4). The presence of the bimodal distribution indicates that San Vittore is exposed to an additional source that the other monitoring sites are not. Although this extra BC source is unknown, we speculate that it is very likely to be freshly emitted wood smoke which 


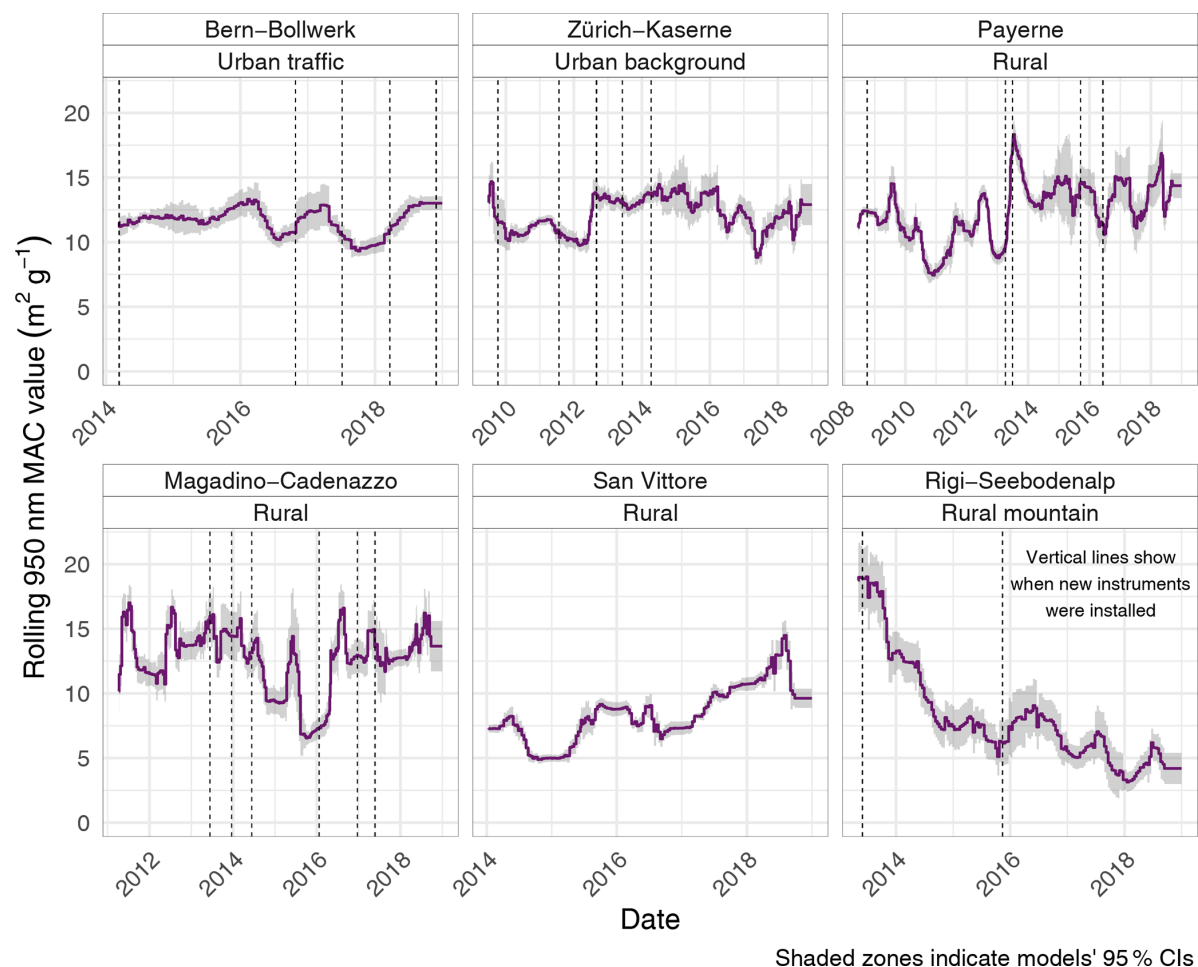

Figure 3. Mass absorption cross-section (MAC) coefficients for $950 \mathrm{~nm}$ for different monitoring sites as calculated by rolling simple linear regression models with windows of $180 \mathrm{~d}$ (alignment of the window was the centre of the period). CI: confidence interval.

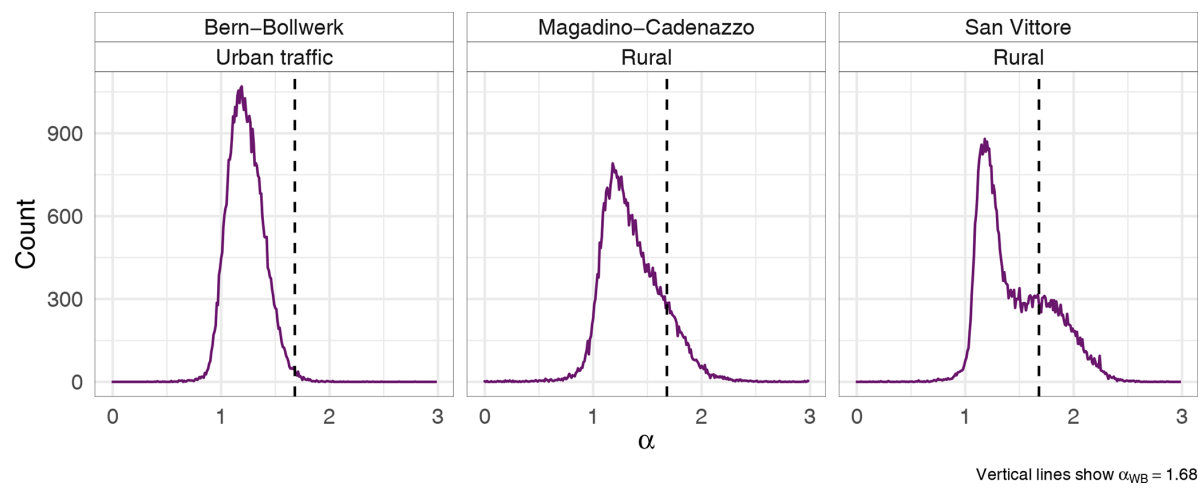

Figure 4. Counts of binned Ångström exponents $(\alpha)$ for three equivalent black carbon (EBC) monitoring sites' hourly absorption observations in Switzerland between 2014 and 2018. The $\alpha$ value has been calculated from seven wavelengths between 370 and $950 \mathrm{~nm}$.

had been emitted near the monitoring location and rapidly transported to the monitoring site before chemical processing had the opportunity to act on the aerosol. The importance of this feature is discussed further in Sect. 3.3. An additional check on the observations was performed in the form of a three-factor receptor model with the multilinear engine (ME-2) as implemented by the EPA PMF (positive-matrixfactorisation) tool (Norris et al., 2014; Brown et al., 2015). However, in this case the factor analysis was unable to resolve the three sources and did not offer any additional con- tribution to the data analysis. Time series of the calculated $\alpha$ values for the six EBC sites are also available in Fig. A4.

\subsection{Diurnal cycles}

Diurnal plots were used to validate if the two components' behaviour were consistent with what is expected of their emission source behaviour after the EBC fractions were calculated with the aethalometer model, and the model's coefficients were evaluated (Fig. 5). With the exception of RigiSeebodenalp, an elevated rural-mountain site, both the traffic and woodburning components' diurnal cycles could be 
readily understood in terms of source activity influencing the monitoring sites. This gives support to the plausibility of the aethalometer model's source apportionment ability.

Bern-Bollwerk, an urban-traffic site displayed a clear morning rush hour peak for $\mathrm{EBC}_{\mathrm{TR}}$ with a decline in concentrations in the late morning, followed by a smaller increase in the afternoon-evening rush hour (Fig. 5). This traffic-forced pattern was also present at Payerne and Zürich-Kaserne, rural and urban-background sites respectively, but at lower concentrations. Magadino-Cadenazzo also displayed a clear twin-peak $\mathrm{EBC}_{\mathrm{TR}}$ diurnal cycle. Here however, the evening peak had approximately the same concentration as the morning peak which was not observed at the other monitoring locations. The strong evening peak was only observed in winter at Magadino-Cadenazzo. This feature was most likely driven by very stable and stagnant atmospheric conditions in the morning and evening because this monitoring site (and surrounding population centres) is located in a deep valley where the day length is short at these times of the year due to confining terrain. This is confirmed by mean bivariate polar plots for Magadino-Cadenazzo where elevated $\mathrm{EBC}_{\mathrm{WB}}$ concentrations were found when wind speeds were very low $\left(\leq 2 \mathrm{~m} \mathrm{~s}^{-1}\right)$, while $\mathrm{EBC}_{\mathrm{TR}}$ sources were identified for a diverse range of wind speeds and directions (Fig. 6).

For most monitoring sites, the $\mathrm{EBC}_{\mathrm{WB}}$ components displayed elevated concentrations in the late evening with a decline in the early morning, consistent with domestic heating demands (Grange et al., 2013). In most cases, this evening peak was followed by a decrease and a lesser morning increase in $\mathrm{EBC}_{\mathrm{WB}}$, likely due to the reignition of woodburning appliances in the morning. However, at the BernBollwerk urban-traffic site, the morning $\mathrm{EBC}_{\mathrm{WB}}$ peak was reminiscent of the $\mathrm{EBC}_{\mathrm{TR}}$ peak, indicating a slight contamination of $\mathrm{EBC}_{\mathrm{WB}}$ by $\mathrm{EBC}_{\mathrm{TR}}$ which the aethalometer model was unable to separate. At Magadino-Cadenazzo, the rural monitoring location which is exposed to a high load of woodburning PM, the diurnal cycle was very clear and strong.

Rigi-Seebodenalp's EBC diurnal cycles were different than the other monitoring locations (Fig. 5). This monitoring site is located at an elevation of $1031 \mathrm{~m}$, is isolated from significant local emissions, and is intermittently in the boundary layer and therefore, at times is not influenced by surface source activities (Grange et al., 2018). These site attributes resulted in EBC diurnal cycles being driven primarily by boundary layer evolution rather than local source strength and activities. When the convective boundary layer grew in vertical extent and exceeded the site's elevation, EBC was mixed to the site, but when the stratified nocturnal boundary layer decoupled the site from surface-based emissions, concentrations remained low (Fig. 5). This feature was clearer for $\mathrm{EBC}_{\mathrm{TR}}$ than $\mathrm{EBC}_{\mathrm{WB}}$, suggesting that traffic, rather than woodburning emissions, are more influential at Rigi-Seebodenalp.

\subsection{Aethalometer model failure}

San Vittore is a small, rather rural settlement located in the Mesolcina Valley in the south of Switzerland (Fig. 2), an area which experiences high concentrations of PM and $\mathrm{BC}$ from residential woodburning. The diurnal plots for San Vittore demonstrate, on average, negative mass contributions for $\mathrm{EBC}_{\mathrm{TR}}$ when $\mathrm{EBC}_{\mathrm{WB}}$ concentrations were high in the evening (averages shown in Fig. 5). This is an implausible situation and indicates the failure of the aethalometer model to correctly apportion the traffic and woodburning $\mathrm{EBC}$ sources. When the time series of the $\mathrm{EBC}_{\mathrm{TR}}$ and $\mathrm{EBC}_{\mathrm{WB}}$ are plotted, the negative contributions are very clear during the colder months, November to December (Fig. 7).

These negative contributions can be managed to some extent by altering the woodburning Ångström exponent $\left(\alpha_{\mathrm{WB}}\right)$, but only with justification. In the case of San Vittore, the $\alpha_{\mathrm{WB}}$ was increased to $\approx 2.0$ (a very high value) in an attempt to eradicate the negative $\mathrm{EBC}_{\mathrm{TR}}$ mass contributions (Fig. 7). This solution only partially resolves the negative $\mathrm{EBC}_{\mathrm{TR}}$ concentrations but also results in the $\mathrm{EBC}_{\mathrm{TR}}$ being estimated at implausibly high concentrations for this location. This is most evident during the cooler periods where $\mathrm{EBC}_{\mathrm{WB}}$ concentrations are high due to a heavy burden of wood smoke, but $\mathrm{EBC}_{\mathrm{TR}}$ concentrations are also high. Based on San Vittore's characteristics, we concluded that the aethalometer model is unable to separate the two EBC components in this time series.

The San Vittore example represents a very clear example of when the aethalometer model fails and the results cannot be used further for data analysis. The aethalometer model fails in this example because the monitoring site is exposed to freshly emitted wood smoke from the nearby residential properties. Woodburning aerosol which has not been exposed to any or very little atmospheric ageing has different special properties than that exposed to atmospheric processing (Jimenez et al., 2009; which was indicated in Fig. 4) and is the explanation for the aethalometer model failure. The aethalometer model's two-source approach is most likely insufficient for the freshly emitted wood smoke which may need to be treated as a third distinct source. A receptor modelling approach (such as PMF) may be a technique which could resolve these three sources, but an investigation of this was outside of the scope of this study. Observations from the San Vittore site were excluded from any further analysis but have been presented to demonstrate that although the aethalometer model can be a useful technique, it is pragmatic and is not appropriate in all cases.

\subsection{EBC dependence on air temperature}

BC emissions from traffic and woodburning sources are not only different in respect to their timing as discussed in Sect. 3.2 but also regarding their dependence on ambient air temperature. Although vehicle emissions of PM are 


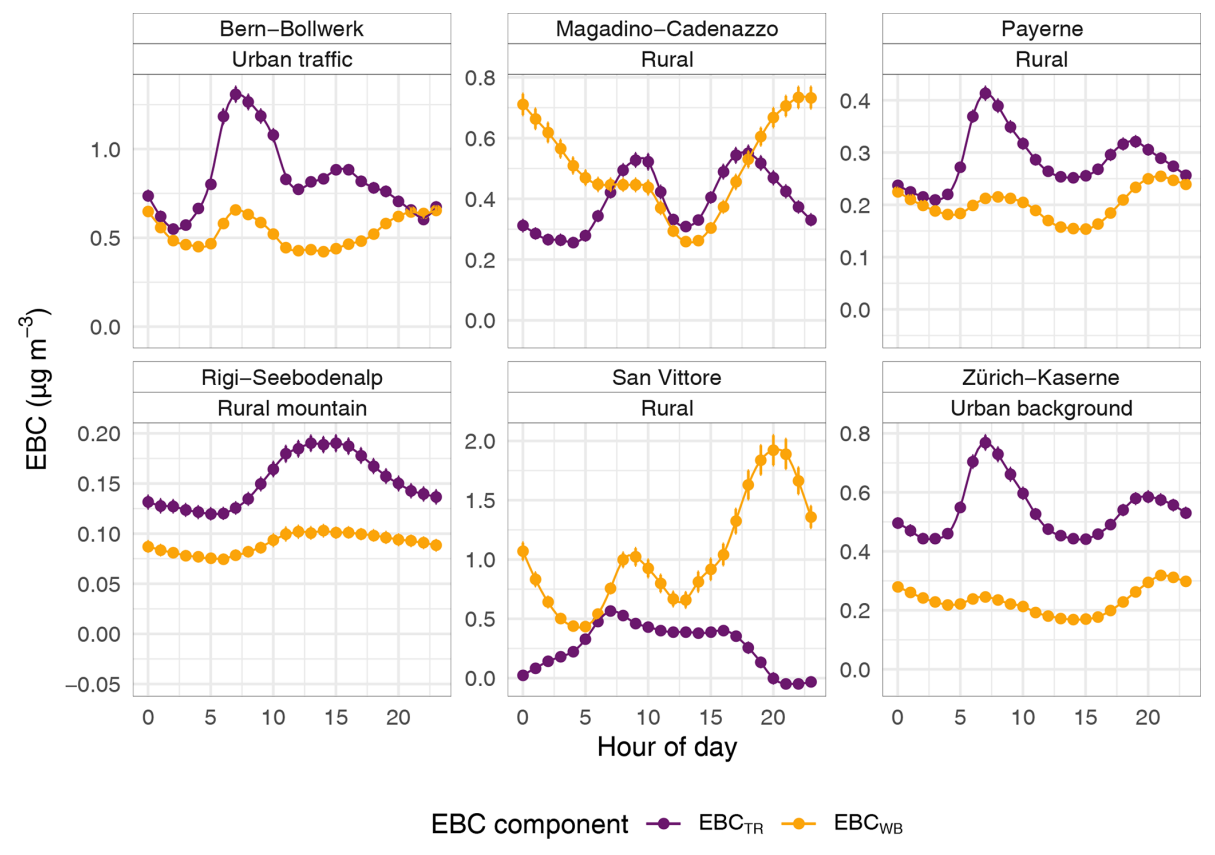

Errors are $95 \% \mathrm{Cls}$

Figure 5. Mean hourly equivalent black carbon (EBC) components for the six monitoring sites. Note the different scales on the $y$ axes. CI: confidence interval.
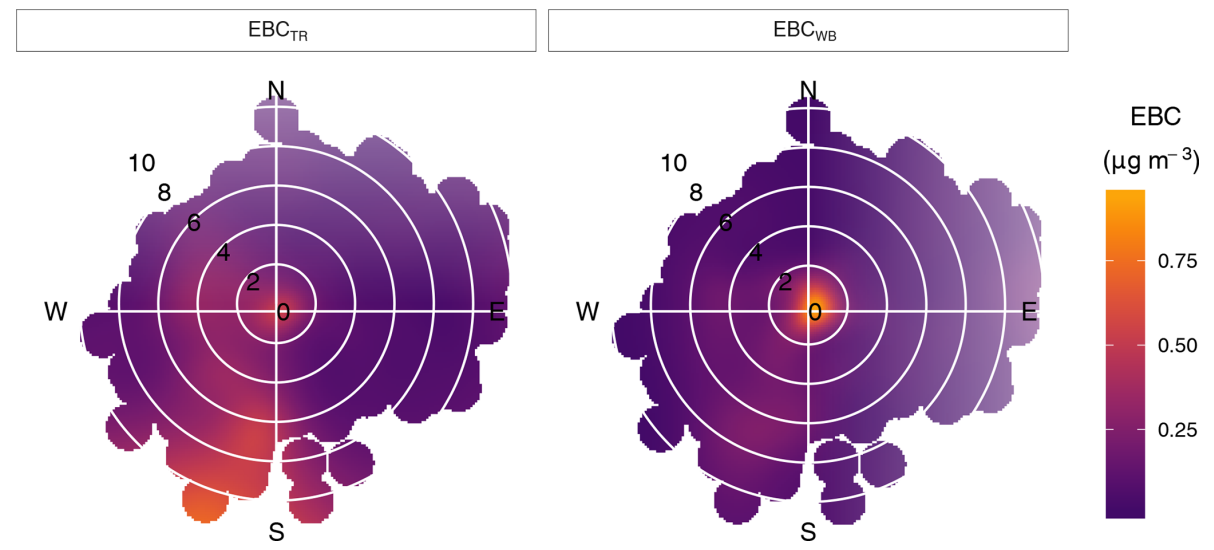

Figure 6. Mean polar plots of equivalent black carbon (EBC) components for Magadino-Cadenazzo between 2011 and 2018 . Fill colours show EBC concentrations by wind speed $\left(\mathrm{ms}^{-1}\right)$ and wind direction.

known to be temperature dependent (Jamriska et al., 2008; Weilenmann et al., 2009), this effect can be expected to be less pronounced when compared to residential heating emissions which have a quite distinct "heating threshold temperature" where emissions will increase as the air temperature decreases further to meet an increasing space heating energy demand. Additionally, in warmer periods, there is very little or no emissions of $\mathrm{BC}$ from residential heating.

These different source patterns were clearly demonstrated for the Swiss EBC monitoring sites with MagadinoCadenazzo $\mathrm{EBC}_{\mathrm{WB}}$ concentrations being negatively correlated with air temperature and with increases in mean
$\mathrm{EBC}_{\mathrm{WB}}$ concentrations once air temperatures were below $12^{\circ} \mathrm{C}$ (Fig. 8). Temperatures of $17^{\circ} \mathrm{C}$ and above resulted in $\mathrm{EBC}_{\mathrm{WB}}$ being less than $0.15 \mu \mathrm{g} \mathrm{m}^{-3}$ at the same location. Payerne's EBC components showed patterns similar to Magadino-Cadenazzo, while the sites which were influenced more by traffic emissions, Bern-Bollwerk and ZürichKaserne, still demonstrated a greater ambient temperature dependence for $\mathrm{EBC}_{\mathrm{WB}}$ than $\mathrm{EBC}_{\mathrm{TR}}$ despite $\mathrm{EBC}_{\mathrm{TR}}$ concentrations being higher for most temperatures.

Due to Rigi-Seebodenalp's elevated location, the patterns observed are different than at the other monitoring sites; in particular as temperature increased so too did $\mathrm{EBC}_{\mathrm{TR}}$ con- 


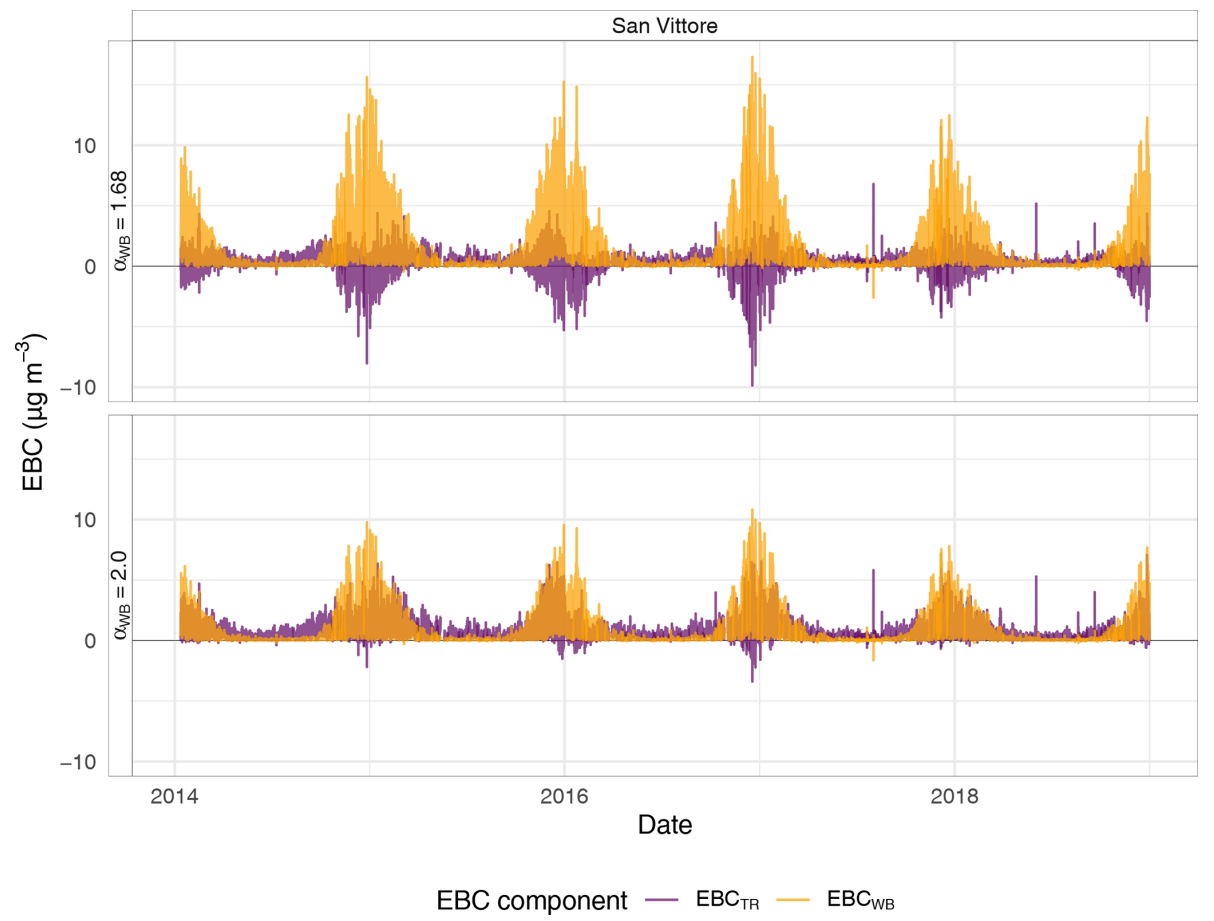

Figure 7. $\mathrm{EBC}_{\mathrm{TR}}$ and $\mathrm{EBC}_{\mathrm{WB}}$ hourly time series between 2014 and 2018 at San Vittore using two values for $\alpha_{\mathrm{WB}}$. The $\alpha_{\mathrm{WB}}$ value of 1.68 was used for the analysis but showed negative contributions of $\mathrm{EBC}_{\mathrm{TR}}$ when $\mathrm{EBC}_{\mathrm{WB}}$ concentrations were high, and using an $\alpha_{\mathrm{WB}}$ value of 2.0 showed implausible $\mathrm{EBC}_{\mathrm{TR}}$ concentrations at this site.

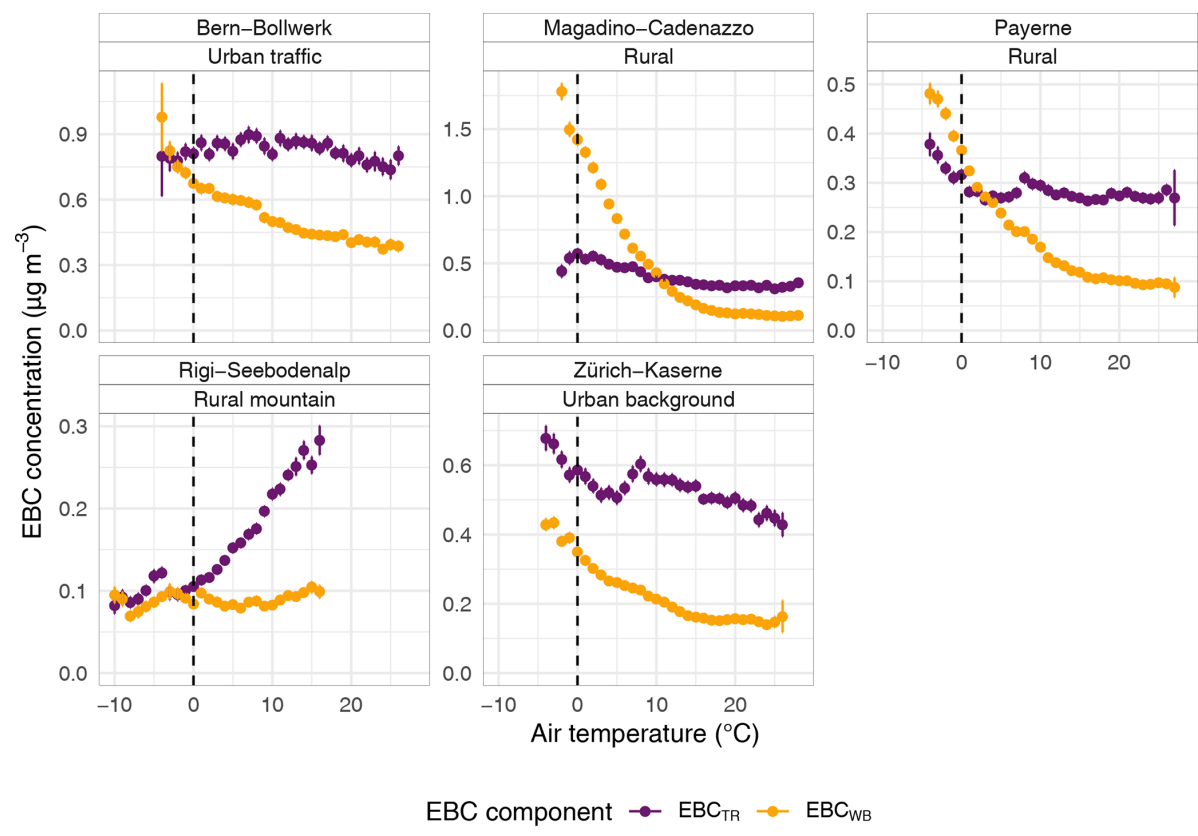

Errors are $95 \% \mathrm{Cls}$

Figure 8. $\mathrm{EBC}_{\mathrm{TR}}$ and $\mathrm{EBC}_{\mathrm{WB}}$ dependence on air temperature for five equivalent black carbon (EBC) monitoring sites in Switzerland. CI: confidence interval. 
centrations (Fig. 8). This was a result of the mixing of trafficsourced pollutants to the monitoring location and shows that Rigi-Seebodenalp is influenced more by traffic emissions than those originating from woodburning activities, which was also suggested by Fig. 5 .

\subsection{Trend analysis}

After the aethalometer model split EBC into the two components, $\mathrm{EBC}_{\mathrm{TR}}$ was found to be significantly decreasing across all monitoring sites in Switzerland between 2008 and 2018, with the exception of the rural-mountain monitoring site, Rigi-Seebodenalp (Fig. 9). Bern-Bollwerk, an urban-traffic site was the most polluted $\mathrm{EBC}$ monitoring site (Table A2) and saw the greatest reduction in $\mathrm{EBC}_{\mathrm{TR}}$ with a decrease of $-0.13 \mu \mathrm{g} \mathrm{m}^{-3}$ year $^{-1}$. Magadino-Cadenazzo, Payerne, and Zürich-Kaserne demonstrated modest significantly decreasing $\mathrm{EBC}_{\mathrm{TR}}$ trends ranging from -0.028 to $-0.059 \mu \mathrm{g} \mathrm{m}^{-3}$ year $^{-1}$ (Fig. 9).

$\mathrm{EBC}_{\mathrm{WB}}$ trends were different than those observed for $\mathrm{EBC}_{\mathrm{TR}}$, even when comparing the same monitoring sites (Fig. 9). The urban monitoring locations, Bern-Bollwerk and Zürich-Kaserne, demonstrated significantly decreasing $\mathrm{EBC}_{\mathrm{WB}}$ trends but at a smaller magnitude when compared to the $\mathrm{EBC}_{\mathrm{TR}}$ components at the same sites. Payerne's $\mathrm{EBC}_{\mathrm{WB}}$ concentrations were also found to be decreasing significantly, but at a minute rate $\left(-0.005 \mu \mathrm{g} \mathrm{m}^{-3}\right.$ year $\left.^{-1}\right)$. The monitoring site which experiences the greatest woodburning PM load, Magadino-Cadenazzo, south of the Alps (Fig. 2), showed no significant trend in the $\mathrm{EBC}_{\mathrm{WB}}$ component (Fig. 9). This is in contrast to the traffic-sourced BC.

Figures 5 and 8 suggested that Rigi-Seebodenalp's isolation from localised BC sources made the site distinct from the other EBC monitoring sites in Switzerland. The trends for Rigi-Seebodenalp were also distinct and showed no significant trend in both the $\mathrm{EBC}_{\mathrm{TR}}$ and $\mathrm{EBC}_{\mathrm{WB}}$ components (Fig. 9).

$\mathrm{EBC}_{\mathrm{TR}}$ trends at Payerne, Magadino-Cadenazzo, and potentially Zürich-Kaserne suggest that breakpoints in the observations are present at the middle of 2013 (Fig. 9). Curiously, these changes were not observable in the absorption observations themselves but could be detected in the calculated $\alpha$ value with adaptive Kolmogorov-Zurbenko filters (KZA filters; Zurbenko et al., 1996; Fig. A4). The dates of these small breakpoints could not be robustly traced to operational activities, but they might have been caused by different batches of aethalometer filter tape which were continuously introduced across the monitoring network in 2013. Therefore, these data suggest that these breakpoints are instrument artefacts. The identification of these features reinforces that the use of the aethalometer model is very useful; it is a pragmatic technique which requires careful evaluation.

\section{$3.6 \quad \mathrm{EBC} / \mathrm{PM}_{2.5}$ ratios}

$\mathrm{BC}$ is almost exclusively an anthropogenic pollutant with generally minor and intermittent contributions from wildfires. It is therefore useful to explore the contribution of $\mathrm{BC}$ emission sources on ambient PM concentrations.

The seasonal EBC/ $\mathrm{PM}_{2.5}$ ratios for the five Swiss EBC monitoring sites between 2014 and 2018 are shown in Fig. 10 and show that the ratios were variable among the monitoring sites and seasons. Bern-Bollwerk, the urban-traffic site, had the highest EBC/PM 2.5 ratio, while Payerne and Rigi-Seebodenalp had the lowest. Again, Fig. 10 gave plausibility to the aethalometer model's source apportionment abilities because features such as $\mathrm{EBC}_{\mathrm{WB}}$ had very low contributions in the summer for most sites, even for the biomass-burning-dominated Magadino-Cadenazzo location. However, as suggested by Fig. 5, Bern-Bollwerk's $\mathrm{EBC}_{\mathrm{WB}}$ contribution to $\mathrm{PM}_{2.5}$ was most likely too high, indicating that the aethalometer model was unable to fully separate the two $\mathrm{EBC}_{\mathrm{TR}}$ and $\mathrm{EBC}_{\mathrm{WB}}$ fractions completely for this particular monitoring site.

On first inspection, the $\mathrm{EBC}_{\mathrm{TOT}}$ contribution to $\mathrm{PM}_{2.5}$ mass seems modest, ranging from $6 \%$ to $14 \%$ depending on site and season. Compare these values to the largest $\mathrm{Eu}$ ropean urban areas, Paris and London, where $\mathrm{BC} / \mathrm{PM}_{2.5}$ ratios (at single heavily trafficked locations) of $43 \pm 20 \%$ and $\approx 50 \%$ respectively have been reported (Ruellan and Cachier, 2001; Grange et al., 2016).

The discussion above is focused on the contribution of EBC to PM. In addition, BC should be to reduced to the lowest possible level because of its classification as a Group 1 carcinogen by the International Agency for Research on Cancer (IARC; entered as soot; International Agency for Research on Cancer, 2019). The reduction of soot emissions also has co-benefits for reducing climate warming effects, and this can also be used for the motivation for the implementation of soot control at the source.

\section{Conclusions}

Using aethalometers for $\mathrm{EBC}$ monitoring allows for the application of the aethalometer model to split $\mathrm{EBC}$ into $\mathrm{EBC}_{\mathrm{TR}}$ and $\mathrm{EBC}_{\mathrm{WB}}$ components. The aethalometer model is a useful and pragmatic data processing technique, but it requires evaluation before using the model's outputs for further data analysis activities. Based on the results presented using Swiss aethalometer observations from six sites between 2008 and 2018, these recommendations can be offered to other data users:

- Values used for the mass absorption cross-section (MAC) coefficients and the Angström exponents $(\alpha)$ should be checked with the observational record, which is being analysed to ensure they are plausible for use with the particular data set. EC observations are how- 


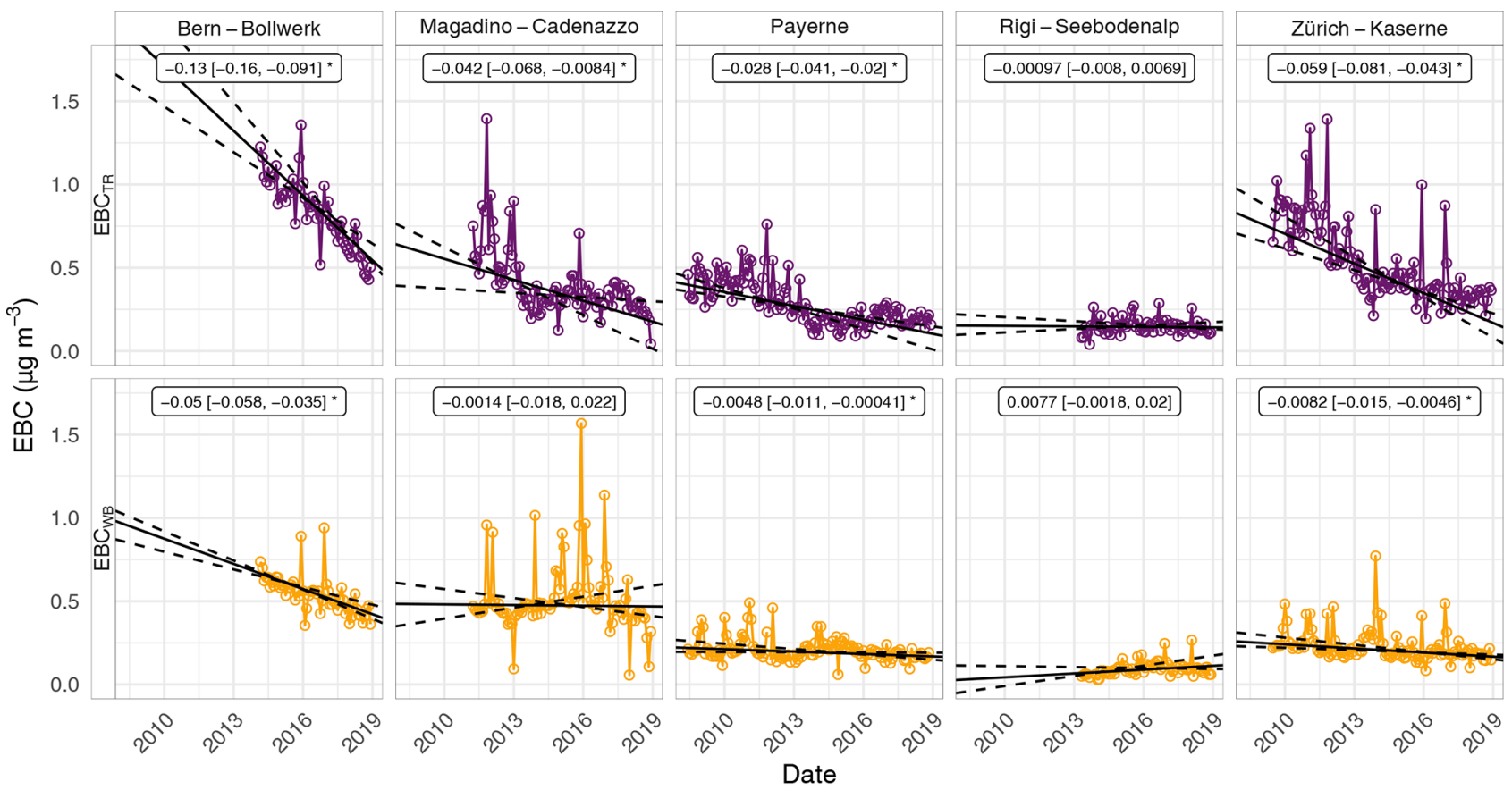

Slope [lower, upper] is $95 \%$ in units per year, and * indicates a significant trend.

Figure 9. Deseasonalised trends of $\mathrm{EBC}_{\mathrm{TR}}$ and $\mathrm{EBC}_{\mathrm{WB}}$ at five $\mathrm{EBC}$ monitoring sites in Switzerland between 2008 and 2018. Slope is the $95 \%$ CI. CI: confidence interval.
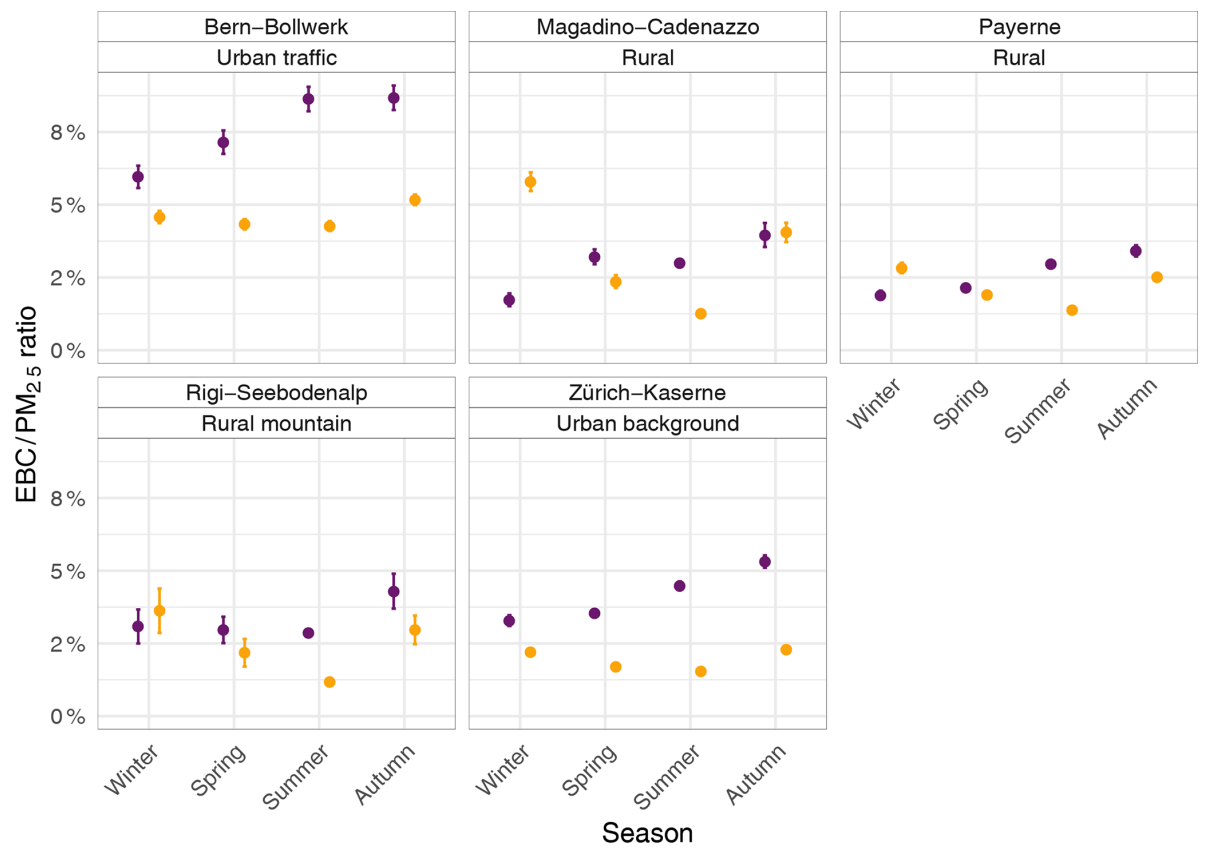

$\mathrm{EBC}$ component $\rightarrow \mathrm{EBC}_{\mathrm{TR}} \rightarrow \mathrm{EBC}_{\mathrm{WB}}$

Errors are $95 \% \mathrm{Cls}$

Figure 10. Seasonal equivalent black carbon $(\mathrm{EBC}) / \mathrm{PM}_{2.5}$ ratios for five monitoring sites in Switzerland between 2014 and 2018 . CI: confidence interval. 
ever required for the calculation of MACs, and therefore, the expansion of monitoring networks to include regular EC samples is recommended for better exploitation of aethalometer absorption data.

- Evaluate the calculated $\mathrm{EBC}_{\mathrm{TR}}$ and $\mathrm{EBC}_{\mathrm{WB}}$ by investigating the presence of negative mass contributions, their diurnal cycles, and ambient temperature dependence to ensure these features are consistent with what is known about the sites' PM load and relevant physical and chemical atmospheric processes.

- If available, put the $\mathrm{EBC}_{\mathrm{TR}}$ and $\mathrm{EBC}_{\mathrm{WB}}$ in context by using PM mass concentrations.

These recommendations will help those who are interested in applying the aethalometer model, which has a rather low barrier to entry.
Despite the failure of the aethalometer model to produce value outputs for one of the six monitoring sites analysed, $\mathrm{EBC}_{\mathrm{TR}}$ and $\mathrm{EBC}_{\mathrm{WB}}$ were successfully analysed separately at five locations, and different trends were observed for the two EBC components. $\mathrm{EBC}_{\mathrm{TR}}$ concentrations significantly decreased across all monitoring sites between 2008 and 2018, with the exception of an isolated rural-mountain monitoring location at a maximum rate of $-0.13 \mu \mathrm{g} \mathrm{m}^{-3}$ year $^{-1}$. The trends of $\mathrm{EBC}_{\mathrm{WB}}$ were more variable, and despite some significantly deceasing trends of some monitoring sites, a site known to be heavily burdened by wood smoke showed no significant trend over the 2008 and 2018 monitoring period. The EBC/PM 2.5 ratios for the five monitoring sites showed location and seasonal variability, and the $\mathrm{EBC}$ contribution to $\mathrm{PM}_{2.5}$ was between $6 \%$ and $14 \%$. This $\mathrm{EBC} / \mathrm{PM}_{2.5}$ ratio is low when compared to other heavily trafficked sites in Paris and London. The aethalometer model is a pragmatic and useful data processing technique, but full evaluation is needed to ensure the results are suitable for further data analysis. 


\section{Appendix A}

Table A1. Factory mass absorption cross-section (MAC) coefficients for the AE33 aethalometer (Magee Scientific, 2016).

\begin{tabular}{lrl}
\hline Wavelength $(\mathrm{nm})$ & MAC value $\left(\mathrm{m}^{2} \mathrm{~g}^{-1}\right)$ & Notes \\
\hline 370 & 18.47 & \\
470 & 14.54 & \\
520 & 13.14 & \\
590 & 11.58 & \\
660 & 10.35 & \\
880 & 7.77 & The definition of black carbon (BC) \\
950 & 7.19 & \\
\hline
\end{tabular}

Table A2. Summary statistics for daily equivalent black carbon (EBC) at five monitoring sites in Switzerland between 2008 and 2018 . CI: confidence interval.

\begin{tabular}{lllll}
\hline Site name & Site type & $\mathrm{EBC}_{\mathrm{TOT}}\left(\mu \mathrm{g} \mathrm{m}^{-3}\right)$ & $\mathrm{EBC}_{\mathrm{TR}}\left(\mu \mathrm{g} \mathrm{m}^{-3}\right)$ & $\mathrm{EBC}_{\mathrm{WB}}\left(\mu \mathrm{g} \mathrm{m}{ }^{-3}\right)$ \\
\hline Bern-Bollwerk & Urban traffic & $1.37 ; 95 \%$ CI [1.34, 1.39] & $0.83 ; 95 \%$ CI [0.82, 0.85] & $0.53 ; 95 \%$ CI [0.52, 0.55] \\
Zürich-Kaserne & Urban background & $0.77 ; 95 \%$ CI [0.76, 0.79] & $0.54 ; 95 \%$ CI [0.53, 0.55] & $0.23 ; 95 \%$ CI [0.23, 0.24] \\
Payerne & Rural & $0.49 ; 95 \%$ CI [0.48, 0.50] & $0.29 ; 95 \%$ CI [0.28, 0.29] & $0.20 ; 95 \%$ CI [0.20, 0.21] \\
Magadino-Cadenazzo & Rural & $0.90 ; 95 \%$ CI [0.87, 0.93] & $0.39 ; 95 \%$ CI [0.38, 0.41] & $0.50 ; 95 \%$ CI [0.48, 0.52] \\
Rigi-Seebodenalp & Rural mountain & $0.24 ; 95 \%$ CI [0.23, 0.25] & $0.15 ; 95 \%$ CI [0.15, 0.16] & $0.09 ; 95 \%$ CI [0.09, 0.10] \\
\hline
\end{tabular}

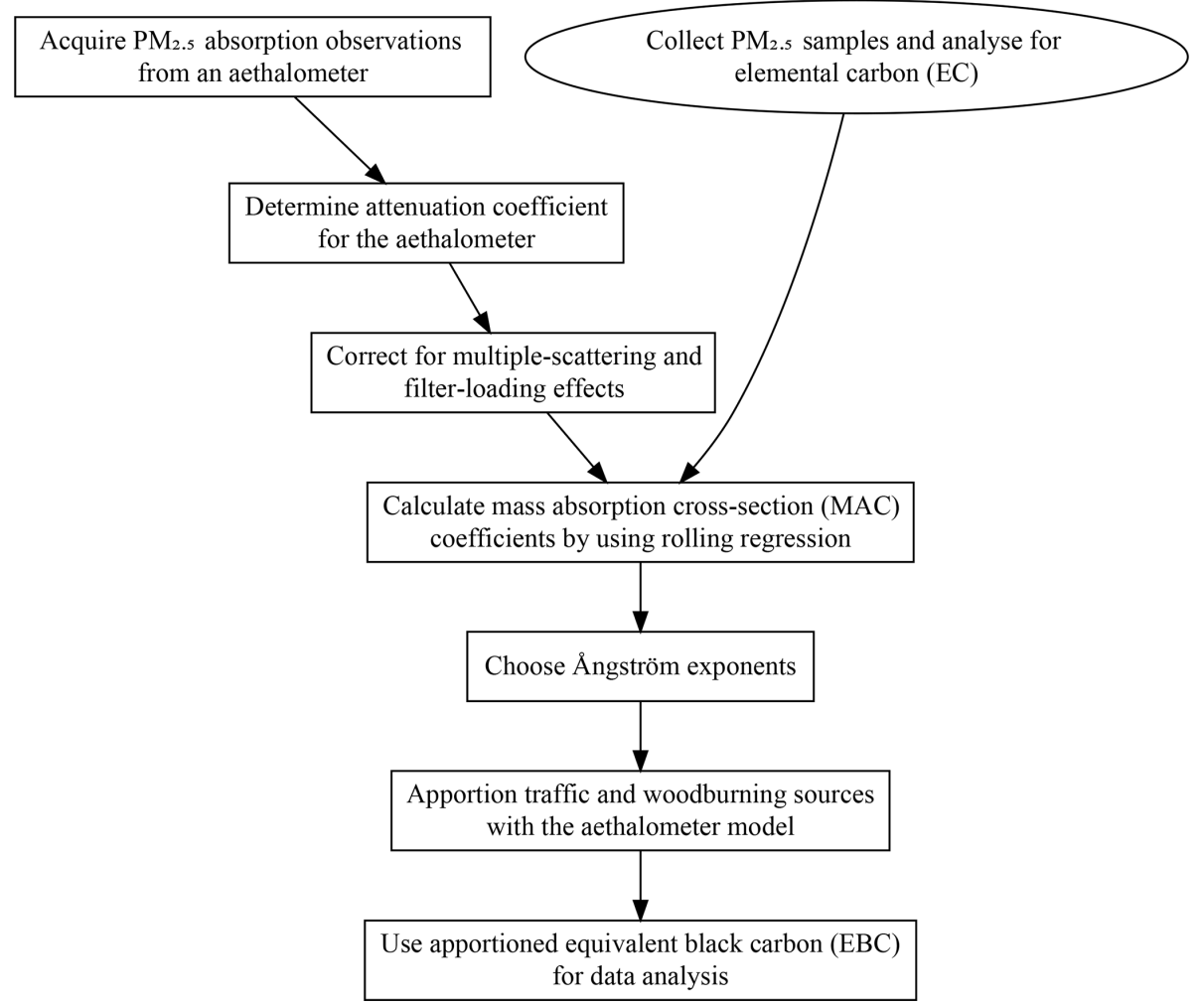

Figure A1. A flow chart of the data processing steps used to apply the aethalometer model. 


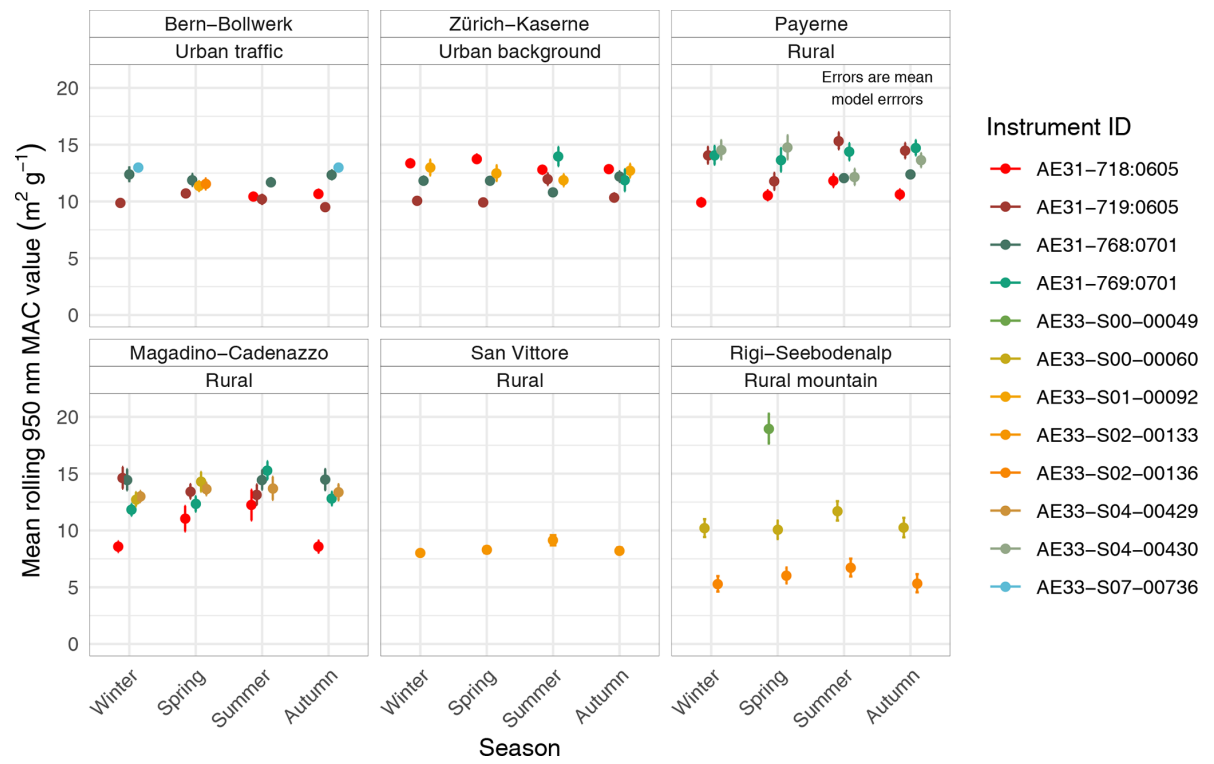

Figure A2. Mean seasonal and instrumental mass absorption cross-section (MAC) coefficients for 950 nm for six equivalent black carbon (EBC) monitoring sites in Switzerland between 2008 and 2018.

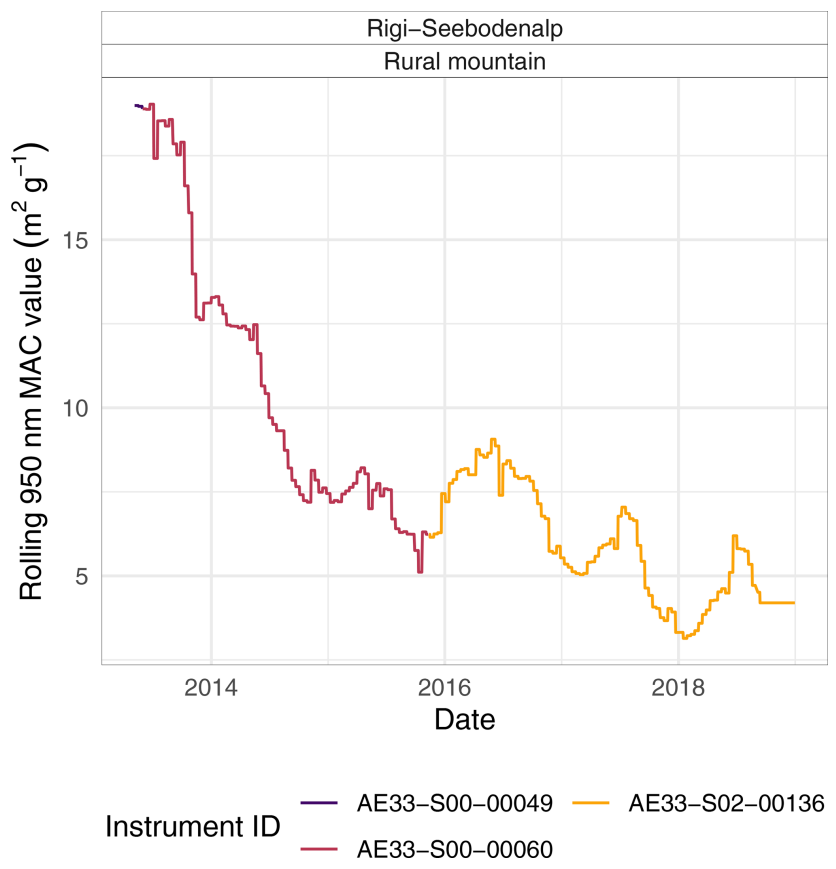

Figure A3. Mass absorption cross-section (MAC) coefficient values for $950 \mathrm{~nm}$ at Rigi-Seebodenalp coloured by the aethalometers which were operating at the monitoring site. 


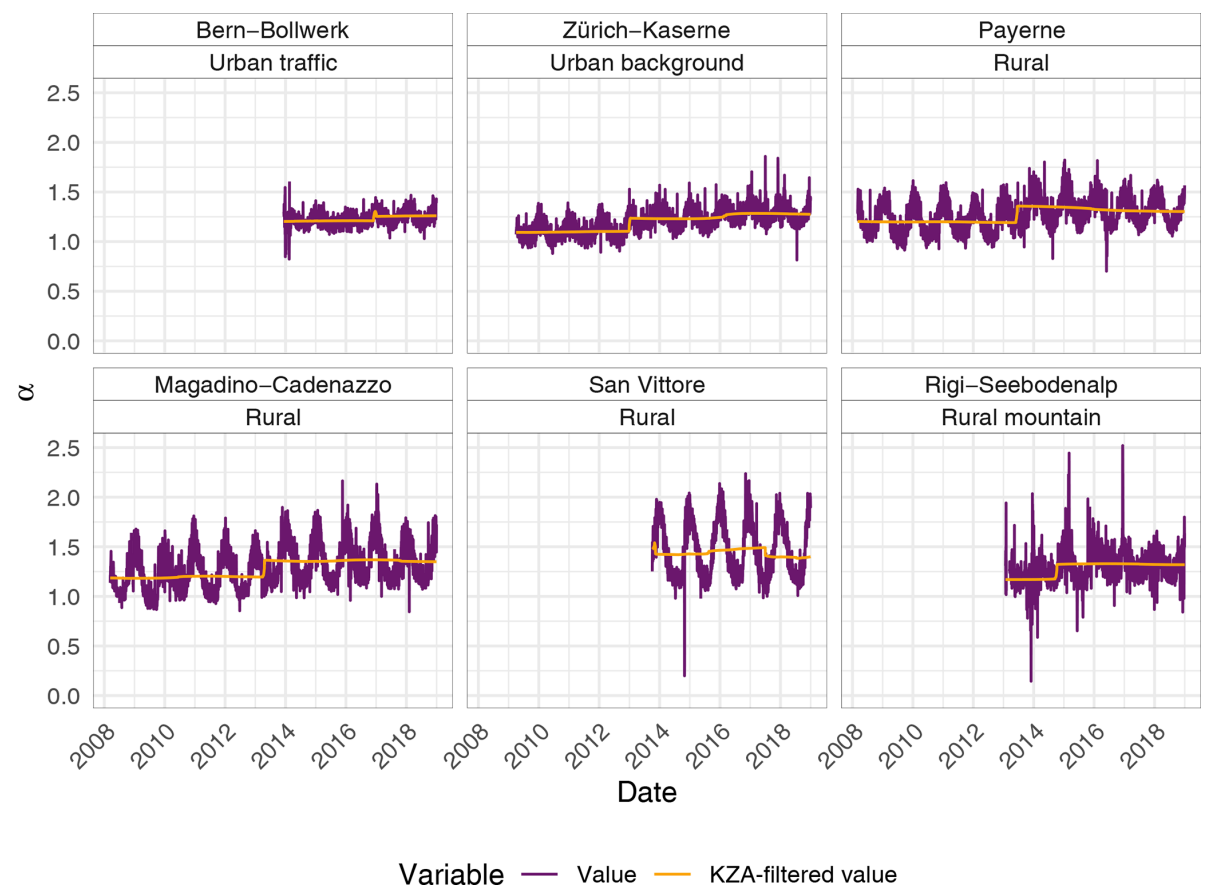

Figure A4. Time series of daily and adaptive Kolmogorov-Zurbenko-filtered (KZA) Ångström exponents ( $\alpha$ ) for six equivalent black carbon (EBC) monitoring sites' absorption observations in Switzerland between 2008 and 2018. The $\alpha$ value has been calculated by wavelengths between 370 and $950 \mathrm{~nm}$. 
Code and data availability. The data sources used in this work are described and are publicly accessible in a persistent data repository (https://doi.org/10.5281/zenodo.3626658; Grange, 2020). Additional information about these data is available from the authors on reasonable request.

Author contributions. SKG and CH developed the research questions and conducted the data analysis. HL and AF collected and supplied additional data. SKG and $\mathrm{CH}$ prepared the paper with input from LE.

Competing interests. The authors declare that they have no conflict of interest.

Acknowledgements. Stuart K. Grange is supported by the Natural Environment Research Council (NERC) while holding associate status at the University of York. The authors thank the COST Action CA16109 COLOSSAL (Chemical On-Line cOmpoSition and Source Apportionment of fine aerosoL) for motivating this research.

Financial support. This research has been supported by the Swiss Federal Office for the Environment (FOEN) (grant no. 00.5083.PZ/6FE525E66).

Review statement. This paper was edited by Pierre Herckes and reviewed by three anonymous referees.

\section{References}

Alfarra, M. R., Prevot, A. S. H., Szidat, S., Sandradewi, J., Weimer, S., Lanz, V. A., Schreiber, D., Mohr, M., and Baltensperger, U.: Identification of the Mass Spectral Signature of Organic Aerosols from Wood Burning Emissions, Environ. Sci. Technol., 41, 5770-5777, https://doi.org/10.1021/es062289b, 2007.

Andreae, M. O. and Gelencsér, A.: Black carbon or brown carbon? The nature of light-absorbing carbonaceous aerosols, Atmos. Chem. Phys., 6, 3131-3148, https://doi.org/10.5194/acp-63131-2006, 2006.

Anenberg, Susan, C., Joel, S., Drew, S., Markus, A., Greg, F., Zbigniew, K., Greet, J.-M., Luca, P., Rita, V. D., Elisabetta, V., Lisa, E., Muller Nicholas, Z., Jason, W. J., Martin, W., Volodymyr, D., Kevin, H. W., Johan, K., Frank, R., and Veerabhadran, R.: Global Air Quality and Health Co-benefits of Mitigating Near-Term Climate Change through Methane and Black Carbon Emission Controls, Environ. Health Persp., 120, 831-839, https://doi.org/10.1289/ehp.1104301, 2012.

Bond, T. C., Streets, D. G., Yarber, K. F., Nelson, S. M., Woo, J.-H., and Klimont, Z.: A technology-based global inventory of black and organic carbon emissions from combustion, J. Geophys. Res.-Atmos., 109, D14, https://doi.org/10.1029/2003JD003697, 2004.
Bond, T. C., Doherty, S. J., Fahey, D. W., Forster, P. M., Berntsen, T., DeAngelo, B. J., Flanner, M. G., Ghan, S., Kärcher, B., and Koch, D.: Bounding the role of black carbon in the climate system: A scientific assessment, J. Geophys. Res.-Atmos., 118, 5380-5552, 2013.

Brown, S. G., Eberly, S., Paatero, P., and Norris, G. A.: Methods for estimating uncertainty in PMF solutions: Examples with ambient air and water quality data and guidance on reporting PMF results, Sci. Total Environ., 518-519, 626-635, 2015.

Carslaw, D. C. and Ropkins, K.: openair - An R package for air quality data analysis, Environ. Model. Softw., 27-28, 52-61, 2012.

De Prins, S., Dons, E., Van Poppel, M., Int Panis, L., Van de Mieroop, E., Nelen, V., Cox, B., Nawrot, T. S., Teughels, C., Schoeters, G., and Koppen, G.: Airway oxidative stress and inflammation markers in exhaled breath from children are linked with exposure to black carbon, Environ. Int., 73, 440-446, 2014.

Drinovec, L., Močnik, G., Zotter, P., Prévôt, A. S. H., Ruckstuhl, C., Coz, E., Rupakheti, M., Sciare, J., Müller, T., Wiedensohler, A., and Hansen, A. D. A.: The "dual-spot" Aethalometer: an improved measurement of aerosol black carbon with realtime loading compensation, Atmos. Meas. Tech., 8, 1965-1979, https://doi.org/10.5194/amt-8-1965-2015, 2015.

European Committee for Standardization (CEN): CEN EN 16909: Ambient air - Measurement of elemental carbon (EC) and organic carbon (OC) deposited on filters, German Institute for Standardization, 2017.

European Environment Agency: Status of black carbon monitoring in ambient air in Europe, available at: https://www.eea.europa. eu/publications/status-of-black-carbon-monitoring (last access: 7 April 2020), EEA Technical report. No 18/2013, 2013.

European Environment Agency: AirBase - The European air quality database (Version 8), available at: https://www.eea.europa.eu/data-and-maps/data/ airbase-the-european-air-quality-database- 8 (last access: 7 April 2020), 2014.

European Environment Agency: Black carbon: Better monitoring needed to assess health and climate change impacts, available at: https://www.eea.europa.eu/highlights/ black-carbon-better-monitoring-needed (last access: 7 April 2020), news, published: 10 December 2013, last modified: 21 June 2016.

European Environment Agency: Download of air quality data. Download service for E1a and E2a data, available at: http://discomap.eea.europa.eu/map/fme/AirQualityExport.htm (last access: 7 April 2020), 2019.

Favez, O., Cachier, H., Sciare, J., Sarda-Estève, R., and Martinon, L.: Evidence for a significant contribution of wood burning aerosols to $\mathrm{PM}_{2.5}$ during the winter season in Paris, France, Atmos. Environ., 43, 3640-3644, 2009.

Federal Office for the Environment: Messstationen des NABEL - Stations de mesure NABEL, available at: https://www bafu.admin.ch/dam/bafu/en/dokumente/luft/fachinfo-daten/ nabel-messstationen.pdf.download.pdf/nabel-messstationen.pdf (last access: 7 April 2020), Technischer Bericht NABEL 2013, 2014.

Fuller, G. W., Tremper, A. H., Baker, T. D., Yttri, K. E., and Butterfield, D.: Contribution of wood burning to $\mathrm{PM}_{10}$ in London, Atmos. Environ., 87, 87-94, 2014. 
Grange, S. K.: $\mathrm{R}$ function to calculate equivalent black carbon (EBC) components with the aethalometer model, available at: https://gist.github.com/skgrange/ a458a5f7eafc1efe594e99dc20ff8da3 (last access: 7 April 2020), GitHub Gist, 2019a.

Grange, S. K.: saqgetr: Import Air Quality Monitoring Data in a Fast and Easy Way, available at: https://cran.r-project.org/web/ packages/saqgetr/index.html (last access: 7 April 2020), r package, $2019 \mathrm{~b}$.

Grange, S. K.: Data for publication "Evaluation of equivalent black carbon (EBC) source apportionment using observations from Switzerland between 2008 and 2018", https://doi.org/10.5281/zenodo.3626658, 2020.

Grange, S. K., Salmond, J. A., Trompetter, W. J., Davy, P. K., and Ancelet, T.: Effect of atmospheric stability on the impact of domestic wood combustion to air quality of a small urban township in winter, Atmos. Environ., 70, 28-38, https://doi.org/10.1016/j.atmosenv.2012.12.047, 2013.

Grange, S. K., Lewis, A. C., and Carslaw, D. C.: Source apportionment advances using polar plots of bivariate correlation and regression statistics, Atmos. Environ., 145, 128-134, 2016.

Grange, S. K., Carslaw, D. C., Lewis, A. C., Boleti, E., and Hueglin, C.: Random forest meteorological normalisation models for Swiss PM10 trend analysis, Atmos. Chem. Phys., 18, 6223-6239, https://doi.org/10.5194/acp-18-6223-2018, 2018.

Hansen, A., Rosen, H., and Novakov, T.: The aethalometer An instrument for the real-time measurement of optical absorption by aerosol particles, Sci. Total Environ., 36, 191-196, https://doi.org/10.1016/0048-9697(84)90265-1, 1984.

Harrison, R. M., Beddows, D. C., Jones, A. M., Calvo, A., Alves, C., and Pio, C.: An evaluation of some issues regarding the use of aethalometers to measure woodsmoke concentrations, Atmos. Environ., 80, 540-548, 2013.

Herich, H., Hueglin, C., and Buchmann, B.: A 2.5 year's source apportionment study of black carbon from wood burning and fossil fuel combustion at urban and rural sites in Switzerland, Atmos. Meas. Tech., 4, 1409-1420, https://doi.org/10.5194/amt-4-14092011, 2011.

International Agency for Research on Cancer: List of Classifications, available at: https://monographs.iarc.fr/ list-of-classifications (last access: 3 March 2020), Agents classified by the IARC Monographs, Volumes 1-124, 2019.

Jacobson, M. Z.: Strong radiative heating due to the mixing state of black carbon in atmospheric aerosols, Nature, 409, 695-697, https://doi.org/10.1038/35055518, 2001.

Jamriska, M., Morawska, L., and Mergersen, K.: The effect of temperature and humidity on size segregated traffic exhaust particle emissions, Atmos. Environ., 42, 2369-2382, 2008.

Janssen, Nicole, A. H., Gerard, H., Milena, S.-L., Paul, F., van Bree Leendert, ten Brink Harry, Menno, K., Atkinson Richard, W., Ross, A. H., Bert, B., and Cassee Flemming, R.: Black Carbon as an Additional Indicator of the Adverse Health Effects of Airborne Particles Compared with $\mathrm{PM}_{10}$ and $\mathrm{PM}_{2.5}$, Environ. Health Persp., 119, 1691-1699, https://doi.org/10.1289/ehp.1003369, 2011.

Jimenez, J. L., Canagaratna, M. R., Donahue, N. M., Prevot, A. S. H., Zhang, Q., Kroll, J. H., DeCarlo, P. F., Allan, J. D., Coe, H., Ng, N. L., Aiken, A. C., Docherty, K. S., Ulbrich, I. M., Grieshop, A. P., Robinson, A. L., Duplissy, J., Smith, J. D., Wil- son, K. R., Lanz, V. A., Hueglin, C., Sun, Y. L., Tian, J., Laaksonen, A., Raatikainen, T., Rautiainen, J., Vaattovaara, P., Ehn, M., Kulmala, M., Tomlinson, J. M., Collins, D. R., Cubison, M. J., Dunlea, J., Huffman, J. A., Onasch, T. B., Alfarra, M. R., Williams, P. I., Bower, K., Kondo, Y., Schneider, J., Drewnick, F., Borrmann, S., Weimer, S., Demerjian, K., Salcedo, D., Cottrell, L., Griffin, R., Takami, A., Miyoshi, T., Hatakeyama, S., Shimono, A., Sun, J. Y., Zhang, Y. M., Dzepina, K., Kimmel, J. R., Sueper, D., Jayne, J. T., Herndon, S. C., Trimborn, A. M., Williams, L. R., Wood, E. C., Middlebrook, A. M., Kolb, C. E., Baltensperger, U., and Worsnop, D. R.: Evolution of Organic Aerosols in the Atmosphere, Science, 326, 1525-1529, 2009.

Kirchstetter, T. W., Novakov, T., and Hobbs, P. V.: Evidence that the spectral dependence of light absorption by aerosols is affected by organic carbon, J. Geophys. Res., 109, D21, https://doi.org/10.1029/2004jd004999, 2004.

Laeremans, M., Dons, E., Avila-Palencia, I., Carrasco-Turigas, G., Orjuela-Mendoza, J. P., Anaya-Boig, E., Cole-Hunter, T., De Nazelle, A., Nieuwenhuijsen, M., and Standaert, A.: Black carbon reduces the beneficial effect of physical activity on lung function, Med. Sci. Sport. Exer., 50, 1875-1881, 2018.

Magee Scientific: Aethalometer Model AE33 User Manual, version 1.54, Aerosol d.o.o., Ljubljana, Slovenia, 2016.

Magee Scientific: Discontinuation/Model AE31-22, available at: https://mageesci.com/discontinuation-model-ae31-22/ (last access: 7 April 2020), 2017.

Magee Scientific: AE33 Aethalometer, available at: https: //mageesci.com/mproducts/model-ae33-aethalometer/ (last access: 7 April 2020), 2019.

Moosmüller, H., Chakrabarty, R. K., Ehlers, K. M., and Arnott, W. P.: Absorption Ångström coefficient, brown carbon, and aerosols: basic concepts, bulk matter, and spherical particles, Atmos. Chem. Phys., 11, 1217-1225, https://doi.org/10.5194/acp11-1217-2011, 2011.

Norris, G., Duvall, R., Brown, S., and Bai, S.: EPA Positive Matrix Factorization (PMF) 5.0 Fundamentals and User Guide, available at: https://www.epa.gov/air-research/ epa-positive-matrix-factorization-50-fundamentals-and-user-guide (last access: 7 April 2020), U.S. Environmental Protection Agency, EPA/600/R-14/108, April 2014.

OpenStreetMap contributors: OpenStreetMap, available at: http:// www.openstreetmap.org (last access: 13 March 2020), 2019.

Petzold, A., Ogren, J. A., Fiebig, M., Laj, P., Li, S.-M., Baltensperger, U., Holzer-Popp, T., Kinne, S., Pappalardo, G., Sugimoto, N., Wehrli, C., Wiedensohler, A., and Zhang, X.-Y.: Recommendations for reporting "black carbon" measurements, Atmos. Chem. Phys., 13, 8365-8379, https://doi.org/10.5194/acp13-8365-2013, 2013.

Ramanathan, V. and Carmichael, G.: Global and regional climate changes due to black carbon, Nat. Geosci., 1, 221-227, https://doi.org/10.1038/ngeo156, 2008.

R Core Team: R: A Language and Environment for Statistical Computing, R Foundation for Statistical Computing, Vienna, Austria, available at: https://www.R-project.org/ (last access: 7 April 2020), 2019.

Reche, C., Querol, X., Alastuey, A., Viana, M., Pey, J., Moreno, T., Rodríguez, S., González, Y., Fernández-Camacho, R., de la Rosa, J., Dall'Osto, M., Prévôt, A. S. H., Hueglin, C., Harrison, R. M., and Quincey, P.: New considerations for PM, Black Carbon and 
particle number concentration for air quality monitoring across different European cities, Atmos. Chem. Phys., 11, 6207-6227, https://doi.org/10.5194/acp-11-6207-2011, 2011.

Ruellan, S. and Cachier, H.: Characterisation of fresh particulate vehicular exhausts near a Paris high flow road, Atmos. Environ., 35, 453-468, 2001.

Sandradewi, J., Prévôt, A., Weingartner, E., Schmidhauser, R., Gysel, M., and Baltensperger, U.: A study of wood burning and traffic aerosols in an Alpine valley using a multiwavelength Aethalometer, Atmos. Environ., 42, 101-112, https://doi.org/10.1016/j.atmosenv.2007.09.034, 2008a.

Sandradewi, J., Prévôt, A. S. H., Szidat, S., Perron, N., Alfarra, M. R., Lanz, V. A., Weingartner, E., and Baltensperger, U.: Using Aerosol Light Absorption Measurements for the Quantitative Determination of Wood Burning and Traffic Emission Contributions to Particulate Matter, Environ. Sci. Technol., 42, 33163323, https://doi.org/10.1021/es702253m, 2008b.

Swiss Federal Office of Topography (swisstopo): The digital height model of Switzerland with a $200 \mathrm{~m}$ grid (DHM25/200m), available at: https://shop.swisstopo.admin.ch/en/products/height_ models/dhm25200 (last access: 7 April 2020), 2010.

Szidat, S., Prévôt, A. S. H., Sandradewi, J., Alfarra, M. R., Synal, H.-A., Wacker, L., and Baltensperger, U.: Dominant impact of residential wood burning on particulate matter in Alpine valleys during winter, Geophys. Res. Lett., 34, L05820, https://doi.org/10.1029/2006GL028325, 2007.

Tarasova, O.: Position of the GAW Scientific Advisory Group on the use of Black Carbon terminology, available at: https://projects. nilu.no//ccc/tfmm/malta_2012/day1/8_GAW_BC-TFMM.pptx (last access: 7 April 2020), 13th annual TFMM meeting, 17-19 April 2012, Gozo, Malta, 2012.
Vignati, E., Karl, M., Krol, M., Wilson, J., Stier, P., and Cavalli, F.: Sources of uncertainties in modelling black carbon at the global scale, Atmos. Chem. Phys., 10, 2595-2611, https://doi.org/10.5194/acp-10-2595-2010, 2010.

Weilenmann, M., Favez, J.-Y., and Alvarez, R.: Cold-start emissions of modern passenger cars at different low ambient temperatures and their evolution over vehicle legislation categories, Atmos. Environ., 43, 2419-2429, 2009.

Weingartner, E., Saathoff, H., Schnaiter, M., Streit, N., Bitnar, B., and Baltensperger, U.: Absorption of light by soot particles: determination of the absorption coefficient by means of aethalometers, J. Aerosol Sci., 34, 1445-1463, https://doi.org/10.1016/S0021-8502(03)00359-8, 2003.

Weinhold, B.: Global bang for the buck: cutting black carbon and methane benefits both health and climate, Environ. Health Persp., 120, A245, https://doi.org/10.1289/ehp.120-a245b, 2012.

Zeileis, A. and Grothendieck, G.: zoo: S3 Infrastructure for Regular and Irregular Time Series, J. Stat. Softw., 14, 1-27, 2005.

Zotter, P., Herich, H., Gysel, M., El-Haddad, I., Zhang, Y., Močnik, G., Hüglin, C., Baltensperger, U., Szidat, S., and Prévôt, A. S H.: Evaluation of the absorption Ångström exponents for traffic and wood burning in the Aethalometer-based source apportionment using radiocarbon measurements of ambient aerosol, Atmos. Chem. Phys., 17, 4229-4249, https://doi.org/10.5194/acp17-4229-2017, 2017.

Zurbenko, I., Porter, P. S., Gui, R., Rao, S. T., Ku, J. Y., and Eskridge, R. E.: Detecting Discontinuities in Time Series of Upper-Air Data: Development and Demonstration of an Adaptive Filter Technique, J. Climate, 9, 3548-3560, https://doi.org/10.1175/15200442(1996)009<3548:dditso>2.0.co;2, 1996. 